\title{
Research Paper \\ The efficacy of combining therapy cognitive with acceptance and commitment on symptoms of depression and psychosomatic problems firefighters of mashhad city
}

Leila Borhani ${ }^{\mathbf{1}}, \mathbf{K h o d a m o r a d ~ M o m e n i}^{\mathbf{2}}$, Jahangir Karami ${ }^{\mathbf{2}}$, Ali Mashhadi
1. Ph.D Student in Psychology, Department of Psychology, Razi University, Kermanshah, Iran.
2. Associate Professor, Department of Psychology, Razi University, Kermanshah, Iran.
3. Professor, Department of Psychology, Ferdowsi University of Mashhad, Mashhad, Iran.

Citation: Borhani L, Momeni KH, Karami J, Mashhadi A. The efficacy of combining therapy cognitive with acceptance and commitment on symptoms of depression and psychosomatic problems firefighters of mashhad city. J of Psychological Science. 2021; 20(103): 1171-1192.

URL: https://psychologicalscience.ir/article-1-1056-fa.html
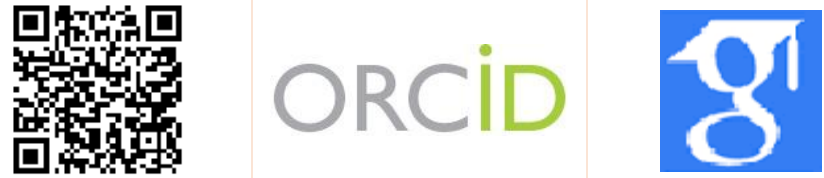

$\underline{10.52547 / J P S .20 .103 .1171}$

\section{A R T I C L E I N F O A B S T RA C T}

Keywords: combining therapy cognitive with acceptance and commitment, symptoms of depression, psychosomatic problems, firefighters

Received: 28 Nov 2020 Accepted: 21 Dec 2020 Available: 23 Sep 2021
Background: Numerous researches have been done on the effect of two therapy cognitive and acceptance and commitment-based treatment on symptoms of depression and psychosomatic problems in the workplace. But the effect of combining therapy cognitive with acceptance and commitment on symptoms of depression and psychosomatic problems in the workplace there is a research gap.

Aims: The aim of present study was the efficacy of combining therapy cognitive with acceptance and commitment on symptoms of depression and psychosomatic problems firefighters of Mashhad city.

Methods: This was a quasi-experimental study with pre-test, post-test, follow up with control group. Statistical population included all 1100 firefighters in Mashhad in 2018. Out of 68 people identified in the screening, 30 subjects were selected by random sampling method and they were randomly divided into two groups (15 persons), one experimental groups and one control group. Research instruments include: depression index: (Beck et al., 1979), Psychosomatic symptoms in nonclinical context: (Mohr., 2000), General Health Questionnaire(Goldberg and Hillier., 1979), and Combining Therapy Cognitive with Acceptance and Commitment Sessions (Hallis., Cameli ., Dionne., Knäuper., 2016). The data were analyzed using repeated measures analysis of variance. Spss software version 22 was used for analysis.

Results: There was a significant difference between the two groups in the posttest in symptoms of depression and psychosomatic problems. Experimental group showed a significant decrease compared to the control group $(\mathrm{P}<0 / 001)$.

Conclusion: Employees who attended combining therapy cognitive with acceptance and commitment sessions had reduced symptoms of depression and psychosomatic problems. This treatment plan is recommended for high- strain work environments prone to psychological problems such as depression and psychosomatic problems.

* Corresponding Author: Khodamorad Momeni, Associate Professor, Department of Psychology, Razi University, Kermanshah, Iran.

E-mail: Kh.momeni@razi.ac.ir

Tel: (+98) 9181323767

2476-5740/ (C) 2021 The Authors. This is an open access article under the CC BY-NC-ND license

(https://creativecommons.org/licenses/by-nc/4.0/). 


\section{Extended Abstract}

\section{Introduction}

Depression is increasingly recognized as a mental health problem in the workplace that leads to reduced productivity and economic burden for organizations (Yunus et al., 2018). Depression is more common in firefighters than in the general population. The prevalence of major depressive disorder among nonUS firefighters is 3.8 to 5.5 percent (Lima et al., 2015; Sakuma et al., 2015; Schepis et al., 2011) and among American firefighters is more than 22 percent (Fullerton, 2004). Psychosomatic problems are another type of illness caused by stress in the workplace, the range of which is very diverse, such as tension headaches, back pain, neck pain, back pain, gastritis, stomach ulcers, asthma, cardiovascular diseases, migraines, etc.( Mein et al., 2000). Due to the nature of their work, firefighters are known as a group at high risk of complications and psychological problems, such as depression, psychosomatic problems and post-traumatic stress disorder. Productivity and quality of firefighting services and reducing their error is essential (Haslam \& Mallon, 2003; Fullerton et al., 2004). Cognitive-behavioral therapy and acceptance and commitment therapy are some of the psychotherapeutic methods considered for depression and psychosomatic problems. Cognitive therapy for depression has been introduced by a special group of the American Psychological Association as a well-known treatment with a strong research background (Butler et al., 2006). On the other hand, A-Tjak et al. (2015) in a meta-analysis showed that acceptance and commitment-based therapy is as effective as cognitive therapy in treating depression, psychosomatic problems, anxiety disorders and addiction.

Research background shows the limitations and strengths of each of the cognitive methods and treatment based on acceptance and commitment as a unit in the effectiveness of treatment of depression and psychosomatic problems. Many studies have examined the effectiveness and comparison of cognitive therapy and therapy based on acceptance and commitment as single therapies, but little research has been done on the additive effect of these two therapies in combination (Hallis et al., 2016). The underlying logic of combining cognitive therapy with acceptance and commitment therapy and why this combination is done can be presented in two main areas. First of all, some of the results of research on the effectiveness of cognitive-behavioral therapy for depression and psychosomatic problems, which is reflected in meta-analyzes and studies in this field (Tan et al., 2014; Yunus et al., 2018) indicate that In some cases, cognitive-behavioral therapy alone may have weak effects.From this perspective, the combination of reconstruction techniques and modification of some cognitions and behaviors (cognitive therapy) along with improving the level of experiential coping, flexibility and acceptance based on new values (acceptance and commitment therapy), to increase coverage of depression and mental health problems. Body is an essential thing that is achieved in the combination of two treatments. The second area, which is the basis for the combined use of cognitive therapy and acceptance and commitment therapy in this study, despite the differences between these two therapeutic approaches, is the theoretical basis and the ultimate goal of these two therapies.

Hallis et al. (2016) designed a combination cognitive therapy program and acceptance and commitment, the effectiveness of which was investigated in the present study. In a study aimed at determining the feasibility and validity of cognitive combination therapy and acceptance and commitment to a group therapy for depression over a 2-year period, Hallis et al. (2017) performed a 15 -week treatment period in 24 patients. The results showed satisfaction with treatment, a significant reduction in the severity of depression and a significant increase in quality of life at 5 time points. The results supported the acceptability and feasibility of a cognitive combination therapy program and acceptance and commitment.

Because according to the research, no research was found that examines cognitive combination therapy and acceptance and commitment in the workplace and there is a research gap in this area, the present study aims to investigate the effectiveness of cognitive combination therapy and acceptance and commitment (Hallis et al., 2016 ) On depression and 


\section{Monthly Journal of Psychological Science}

Vol. 20, No. 103, Autumn(October) 2021

psychosomatic problems of firefighters. The aim of this study was to answer the question, does combination cognitive therapy and acceptance and commitment affect the symptoms of depression and psychosomatic problems in the workplace?

\section{Method}

The present study was a quasi-experimental pre-testpost-test study with a control group and a follow-up period in terms of applied purpose and research method. The statistical population included about 1100 firefighters in Mashhad in 2018. In order to select a sample, a general health questionnaire was administered in the first screening. Then, through diagnostic interviews based on checklists according to American Psychiatric Association Diagnostic and Statistical Manual (2013), individuals with diagnostic criteria for depression and psychosomatic problems and other inclusion criteria were identified. Out of 68 people identified in the initial screening, 30 were randomly selected. In order to create experimental conditions, 30 people were matched into two groups with equal numbers based on their depression and psychosomatic problems and demographic characteristics. Then one group was randomly selected as the experimental group and one group as the control group.

To measure depression, the Beck Depression Inventory (BDI), a 13-item short form, was used to determine varying degrees of depression from mild to severe (Beck et al., 1979). The Beck Short Depression Inventory has been used by various researchers including Hook (2013) to assess employee depression in the workplace. In the present study, the reliability of this questionnaire using Cronbach's alpha method was 0.93. The Mohr (2000) Non-Clinical Psychiatric Symptoms Questionnaire was used to assess psychosomatic problems. This questionnaire has 20 items that are answered on a 5-point Likert scale from no time to almost every day, and according to this scoring method, the minimum score is 20 and the maximum score is 100. Mohr (2000) mentioned the internal consistency of this questionnaire in different studies with different samples between 0.7 and 0.93 . Mohr (2000) also confirmed the convergent and divergent accuracy of this questionnaire. In the present study, the reliability of this questionnaire was 0.90 using Cronbach's alpha method.

For initial screening, the Goldberg and Hiller (1979) General Health Questionnaire (GHQ-28) with 28 items was used. The scoring method in this questionnaire is Likert method, in which the options are scored from 0 to 3 . In the present study, the reliability of this questionnaire was 0.87 using Cronbach's alpha method. The combination of cognitive therapy and acceptance and commitment package was designed by Hallis et al. (2016) and its effectiveness was investigated in the present study. This treatment package is performed in 15 sessions of 90 minutes and for 15 weeks, one session per week, which was performed in the present study. At the end of the treatment sessions, both groups answered the Depression and Psychosomatic Problems Questionnaire in the post-test phase, which took place one week after the end of the treatment session. The follow-up period took place after 12 months.

In the statistical analysis of the data, at the descriptive level, mean and standard deviation and at the inferential level, repeated measures analysis of variance were used. These analyzes were performed using Spss software version 22.

\section{Results}

In this study, because the number of measurements was more than twice and the number of dependent variables was more than one case, Analysis of variance repeated measurement was used. The intersubject factor (group) and the intra-subject factor (time) and the interaction effect (time $\times$ group) can be examined by this means. Descriptive findings showed that in the control group there was no significant difference between the mean scores of pre-test, posttest and follow-up of dependent variables. Also, there is no significant difference between the test of the experimental group and the control group, which confirms the homogeneity of the experimental group and the control group. Other findings related to the means show that in the experimental group, the mean of the variables of depressive symptoms and psychosomatic problems in the post-test and followup mode decreased compared to the control group, which could indicate the effectiveness of combination therapy. Before examining the research hypotheses, 


\section{Monthly Journal of Psychological Science}

Vol. 20, No. 103, Autumn(October) 2021

first the research data were analyzed separately by groups (experiment-control) and position (pre-testpost-test-follow-up) in terms of normality of the data using Shapiro-Wilk test.

The results of the Shapiro-Wilk test showed that the assumption that the data were normal in the symptoms of depression and psychological problems in the pre-test, post-test and follow-up positions had a normal distribution. The results of the Box's M Test were examined to investigate the assumption of homogeneity of the covariance matrix, which showed that this assumption is valid for the studied components $(\mathrm{P}<0.05)$ Levene's test results also supported the hypothesis of homogeneity of variance error for the variables of depressive symptoms and psychosomatic problems $(\mathrm{P}<0.05)$. Then, the spherical hypothesis was performed using Mochelli test for all the studied variables and the results of this test showed that for the variables, depressive symptoms and psychosomatic problems are established. The results of multivariate analysis of variance tests combined with repeated measures on pre-test, post-test and follow-up scores show that cognitive combination therapy and acceptance and commitment in the time factor (Eta squared $=90.32$, $\mathrm{F}=0.84, \mathrm{P}<0.0001)$ and the interaction effect of time and group $($ Eta squared $=0.78, \mathrm{~F}=75.22, \mathrm{P}<0.0001$ ) is significant. These results indicate that the combined cognitive therapy and the accepted acceptance and commitment are effective.

Table 1. Results of analysis of variance mixed with repeated measures in the text of Manual mixed on pre-test, post-test scores and follow-up depressive symptoms and psychosomatic problems

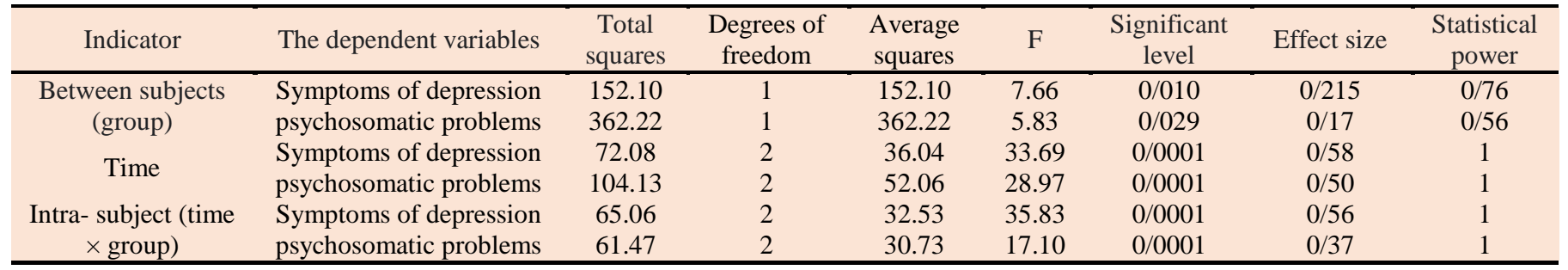

The results of the intergroup effect test in Table 1 showed that there was a significant difference between the experimental and control groups in the variable of depressive symptoms $(\mathrm{F}=66.7, \mathrm{P}<0.01)$ in the experimental and control groups. The results of intra-group effect test showed that the effect of time factor was significant for the variable of depressive symptoms $(\mathrm{F}=69.33, \mathrm{P}<0.0001)$. The interactive effect of time $\times$ group is also significant that the results of this analysis are presented in full in Table 1. These results indicate the effectiveness of cognitive combination therapy and acceptance and commitment on depressive symptoms and the comparison of means showed a decrease in depressive symptoms in the experimental group compared to the control group. Also, there is a significant difference between the experimental and control groups in the variable of psychosomatic problems $(\mathrm{F}=83.5, \mathrm{P}<0.029)$ between the experimental and control groups. The results of intragroup effect test showed that the effect of time factor is significant for the variable of psychosomatic problems $(\mathrm{F}=28.97, \mathrm{P}<0.0001)$. The interaction effect of time $\times$ group is also significant that the results of this analysis are presented in Table 1 . These results indicate the effectiveness of cognitive combination therapy and acceptance and commitment on psychosomatic problems and the comparison of means showed a decrease in psychiatric problems in the experimental group compared to the control group.

Table 2. Bonferroni test results for comparison of pre-test, post-test and follow-up scores

\begin{tabular}{|c|c|c|c|c|c|c|}
\hline The dependent variables & Comparison & Mean difference & standard error & The significance level & Low limit & upper limit \\
\hline \multirow{3}{*}{ Symptoms of depression } & Pre-test - post-test & 2.06 & $0 / 23$ & 0.0001 & 1.46 & 2.67 \\
\hline & Post-test - follow-up & $-0 / 40$ & 0.20 & 0.19 & -0.93 & 0.132 \\
\hline & Pre-test - follow-up & $1 / 66$ & 0.28 & 0.0001 & 0.93 & 2.39 \\
\hline \multirow{3}{*}{ psychosomatic problems } & Pre-test - post-test & 2.02 & 0.40 & 0.0001 & 0.98 & 3.06 \\
\hline & Post-test - follow-up & 0.45 & 0.19 & 0.07 & $-0 / 03$ & 0.93 \\
\hline & Pre-test - follow-up & 2.47 & 0.39 & 0.0001 & 1.46 & 3.48 \\
\hline
\end{tabular}


After the effects of time, group and interaction were significant, the three modes of pre-test, post-test and two-by-two follow-up were compared and analyzed separately with the help of Boferroni post hoc test. The results are reported in Table 2. Findings in Table 2 show that there is a significant difference between pre-test-post-test in the two variables of depressive symptoms and psychosomatic problems $(\mathrm{P}<0.0001)$ In other words, the effect of the intervention is confirmed. There is also a significant difference between pretest-follow-up in two variables $(\mathrm{P}<$ 0.0001). In other words, the effect of time is confirmed. The results also show that there is no significant difference between post-test and followup in the two variables of depressive symptoms and psychological problems.

\section{Conclusion}

The results of the present study showed that cognitive combination therapy and acceptance and commitment were effective in reducing the symptoms of depression and psychosomatic problems of firefighters. The results of the research are directly in line with the results of Lunde \& Nordhus (2009) and Hallis et al. (2017). In explaining the effectiveness of cognitive and acceptance and commitment combination therapy on the symptoms of depression, it should be said that combination therapy includes both cognitive therapy and therapy based on acceptance and commitment in a treatment protocol. These two approaches are complementary and, as individuals understand each of the two approaches, they will be able to decide when to use change techniques (e.g., cognitive reconstruction) and when to use acceptance techniques (e.g., mindfulness). Equipping the individual with a greater number of techniques to help increase flexibility and the selection and application of techniques depending on personal circumstances or characteristics; Thus, in comparison with each of these therapies as a unit, combination therapy provides more techniques for effectiveness (Hallis et al., 2016)

In explaining the effectiveness of cognitive combination therapy and acceptance and commitment on psychosomatic problems, it can be said that the cognitive part of cognitive combination therapy and acceptance and commitment helps people who are able to struggle with their irrational thoughts and beliefs. On the other hand, the acceptance of combination therapy, in which the awareness and acceptance of the body is important, is especially helpful for people who are not able to struggle with their irrational thoughts and beliefs (Cayoun, 2014). Simultaneous use of cognitive therapy and acceptance and commitment therapy facilitates acceptance as an alternative solution in situations where it is difficult for the patient to struggle with irrational thoughts and beliefs. By compromising and reducing internal conflicts, new conditions are created for patients to discuss their valuable lives, and this shifts people's attention from past unsuccessful solutions to the problem-solving realm. This process reduces anxiety and eliminates the cycle of related obsessive thoughts.

\section{Ethical Considerations}

Compliance with ethical guidelines: This article is taken from the doctoral dissertation of the first author in the field of psychology at Razi University of Kermanshah. Participants consciously and voluntarily participated in the research. The principle of confidentiality was observed in the research.

Funding: This study was conducted as a $\mathrm{PhD}$ thesis with no financial support.

Authors' contribution: The first author was the senior author, the second were the supervisors and the third and forth was the advisors.

Conflict of interest: The authors declare no conflict of interest for this study.

Acknowledgments: We would like to thank the supervisors and consultants of this research as well as the staff of the human resources department of the Mashhad Fire Department who assisted in conducting this research. 


\section{آششانى}

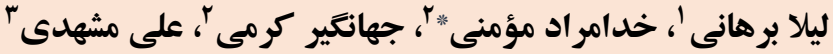

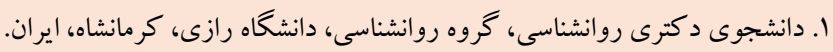

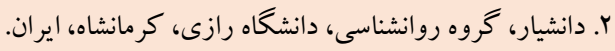

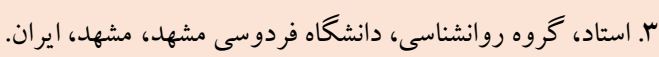

جكيده

زمينه: يزوهشهاى متعددى بيرامون تأثير درمان شناختى و درمان مبتنى بر يذيرش و تعهد بر نشانهاى افسردگى و مشكلات روانتى در

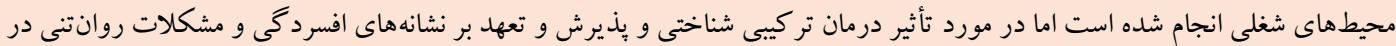
محيط شغلى شكاف تحقيقاتى وجود دارد. هدف: هدف يُزوهش حاضر بررسى اثربخشى درمان تركيبى شناختى و بذايرش و تعهلد بر نشانههاى افسردگى و مشكلات روانتى در

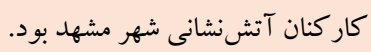

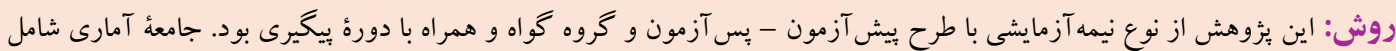

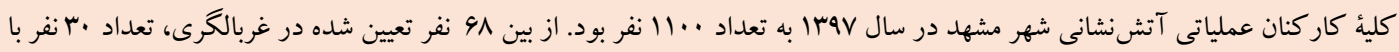

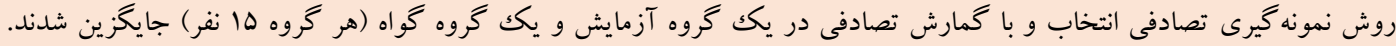

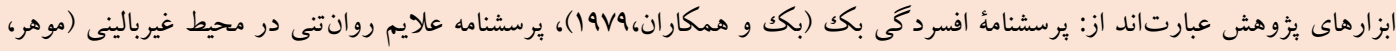

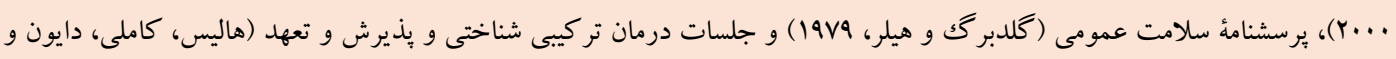

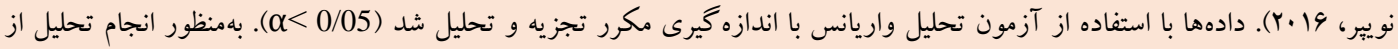
نرم|فزار Spss نسخه r آستفاده شد.

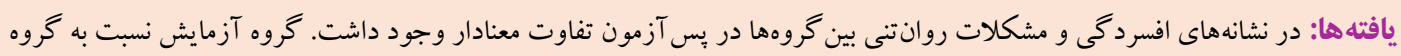
كواه كاهش معنادارى را نشان دادند (

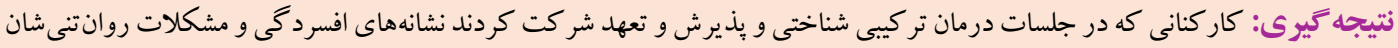

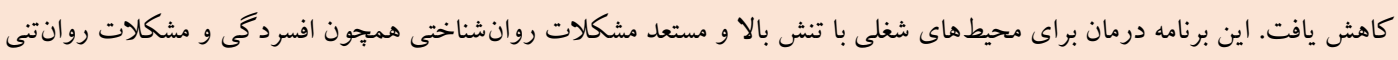
بيشنهاد مى شودد.
مشخصات مقاله

كليدوازهها: درمان تركيبى شناختى و يذيرش و و

تعهد،

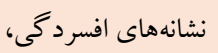
مشكلات روانتنى، كار كنان عملياتى آتشنشانى

* نويسنده مسئول: خدامر اد مؤمنى، دانشيار، گروه روانشناسى، دانشخاه رازى، كرمانشاه، ايران. رايانه: Kh.momeni@ razi.ac.ir 
خطرات جسمانى و روانى زيادى در گير هستند و به طور بيوسته از آنان

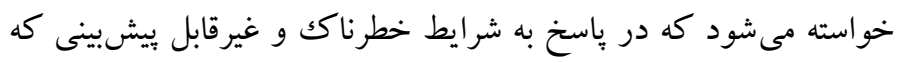

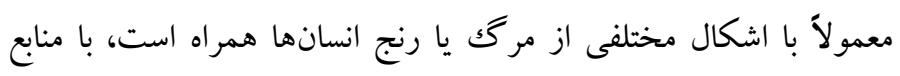
محدود و فشار زياد ازلحاظ محدوديت زمانى اقدام نمايند (اسميس،

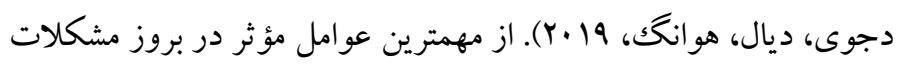

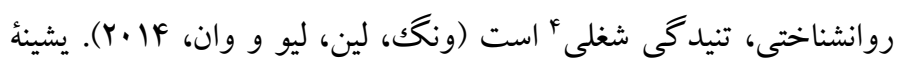

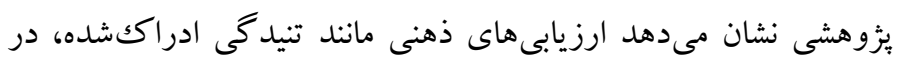

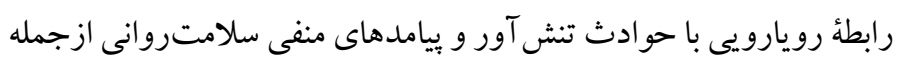

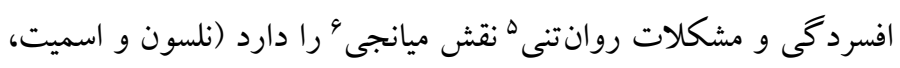

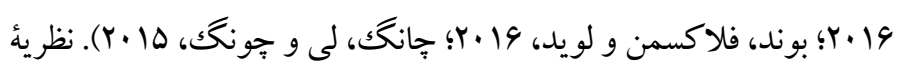

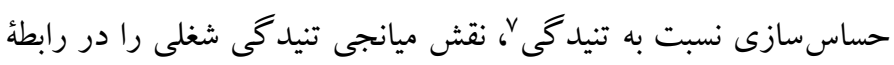
بين حوادث تنش آور و افسردگى را توضيح مىدهد. بر اساس اين نظريه،

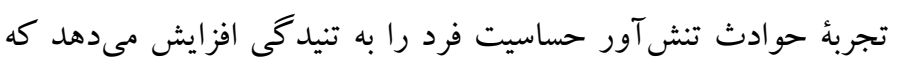

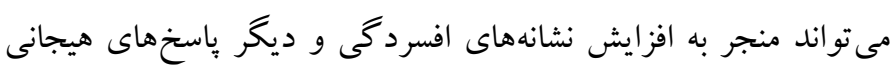

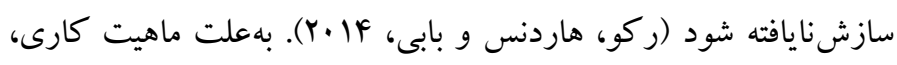

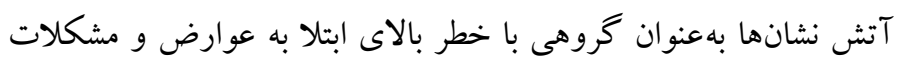

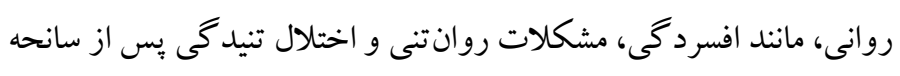

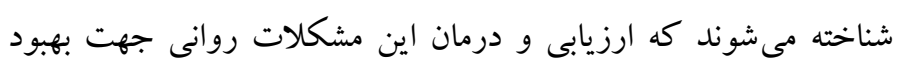

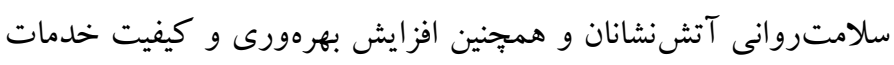
آتشنشانان و كاهش خطاى آنها امرى ضرورى مىباشد (هاسلام و

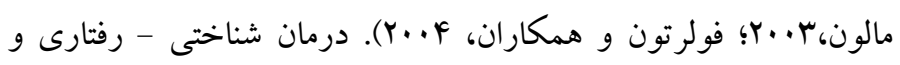

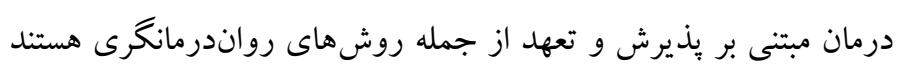

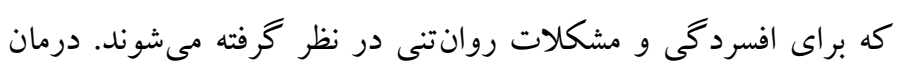
شناختى براى افسردگى، توسط گروه ويزه انجمن روانشناسى آمريكا

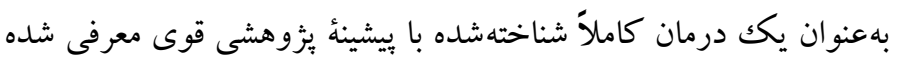

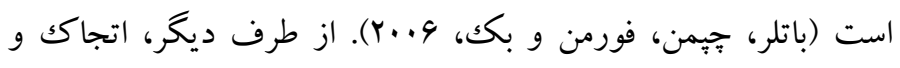

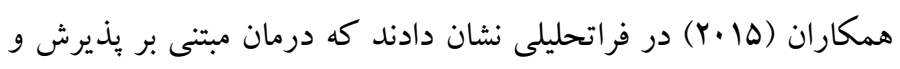
تعهد در درمان افسردگى، مشكلات روانتنى، اختلالات اضطر ابى و اعتياد

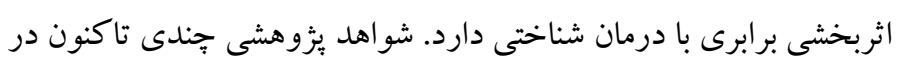

${ }^{5}$. psychosomatic problems

6 . Mediation

${ }^{7}$. stress sensitization theory
مقلفمه

افسردگى بهطور فز آيندهاى بهعنوان يكك مشكل بهداشت روانى در محل

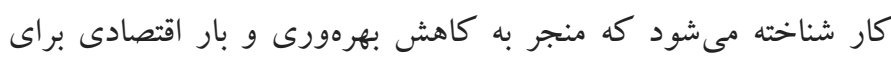

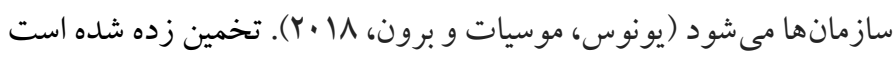
كه افسردگى هر ساله در سطح جهانى با تأثيرى كه بر محيطهاى شغلى أنى،

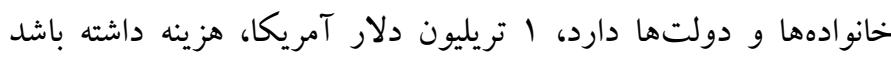

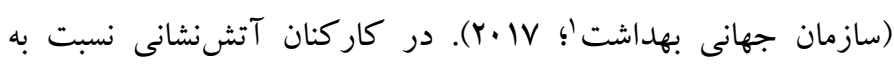
جمعيت عادى شيوع بالاترى از افسردگى ب وجود دارد. شيوع اختلال

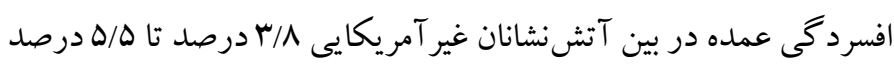

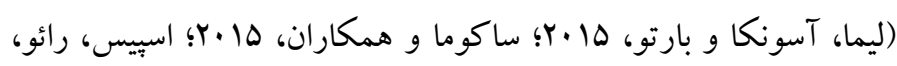

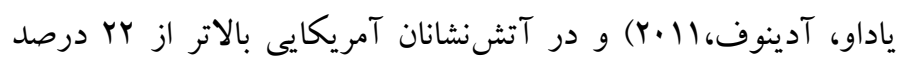

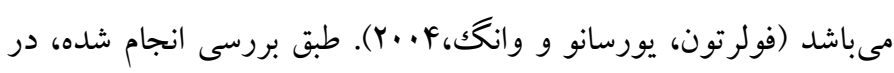

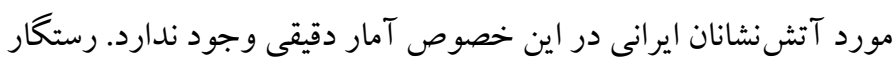

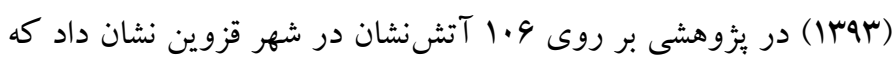

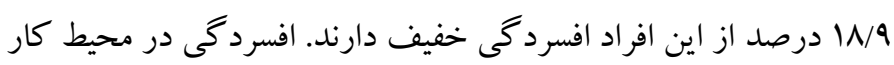

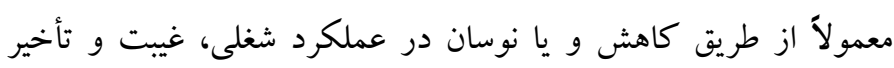

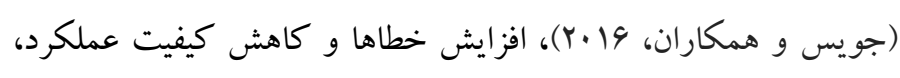
كناره گيرى از همكار ان، حساسيتهاى كلامى و واكنش هاى هيجانى و...

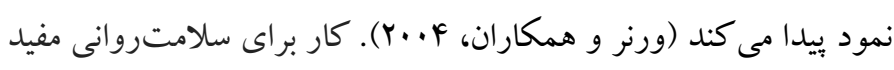

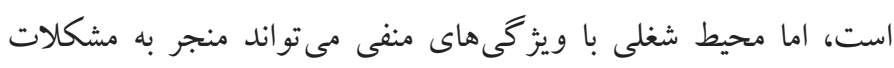

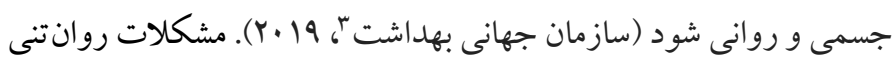

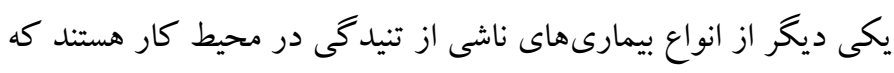

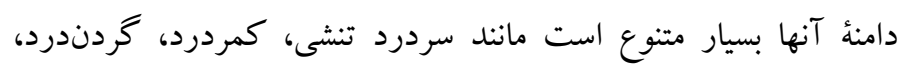

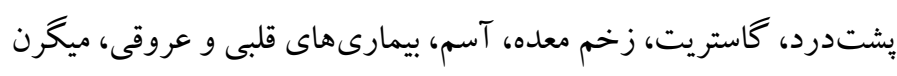

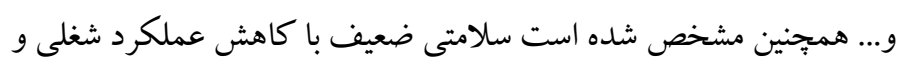

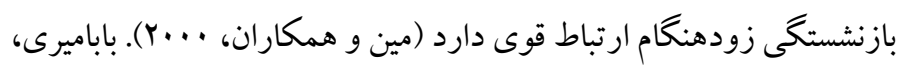

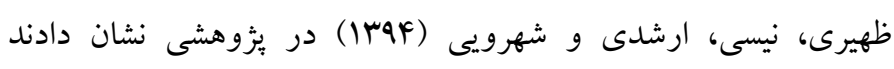

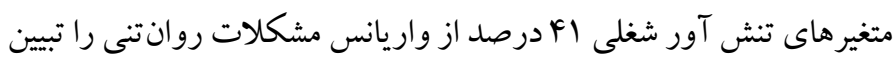

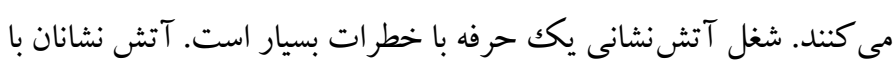

\section{WHO}

${ }^{2}$. depression

${ }^{3}$. World Health Organization

${ }^{4}$. job stress 
و تنيدگى مشاهده نشد؛ بنابر اين اثربخشى فيزيوتر ابى بر اضطر اب، افسردگى و تنيدگى حاصل از درد مزمن مورد تأييد قرار نظخرفت.

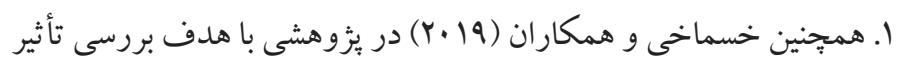

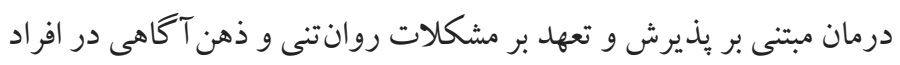

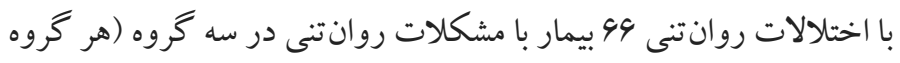
r r نفر) گمارش شدند. نتايج در مراحل بيخيرى و بس بـ آزمون نشان دادند درمان مبتنى بر يذيرش و تعهد مى تو اند سطح مشكلات روانى در افر اد مبتلا

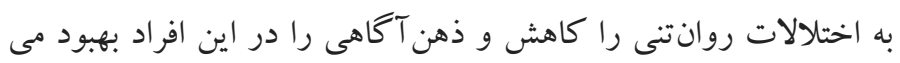

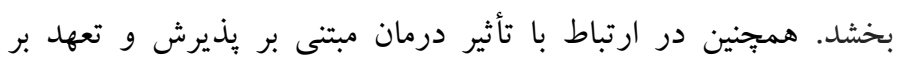

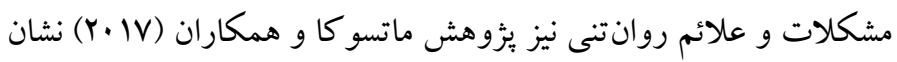

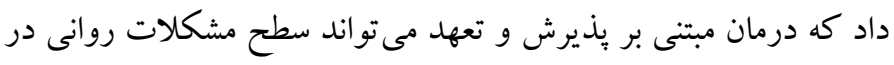

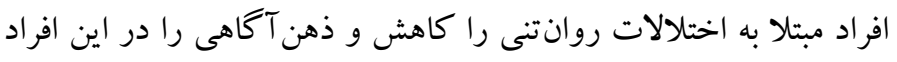
بهبود بخشد. اثربخشى درمان مبتنى بر يذيرش و تعهد بر برخى از علايم و

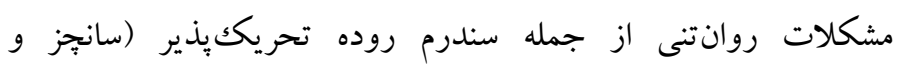

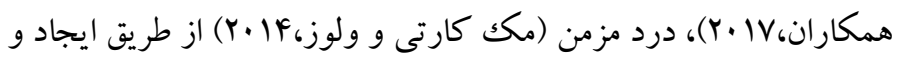

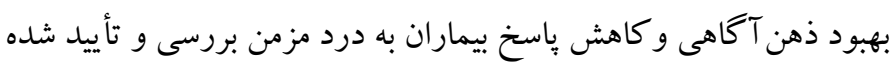

برخلاف بزوهش هاى مورد اشاره در مورد اثربخشى درمانهاى شناختى -

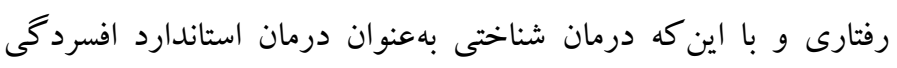

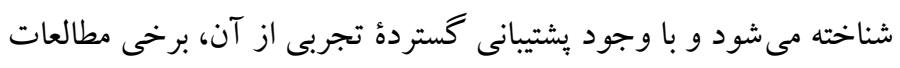

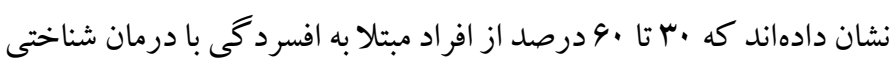
خالص بهبود قابل ملاحظه اى را تجربه نمى كنند (ديميدجيان و همكاران،

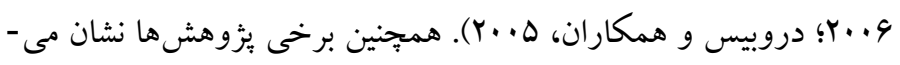

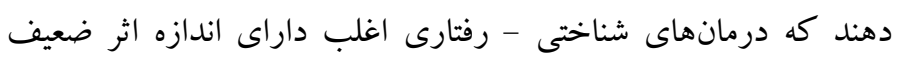

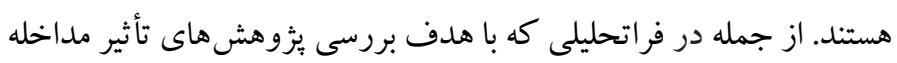

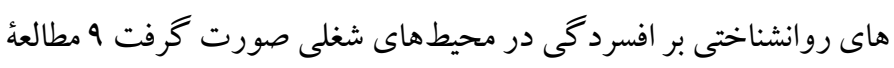

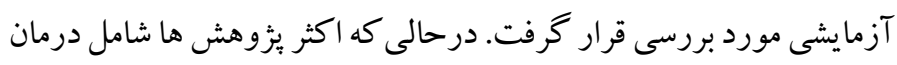

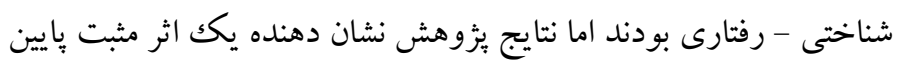

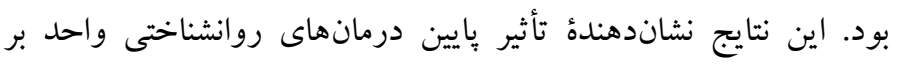

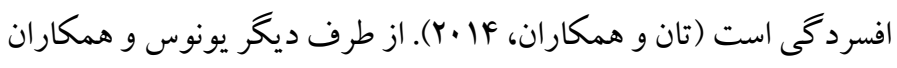
(Y.MA) در فراتحليلى از يزوهش هاى انجام شده در خصوص مداخله هاى كاهش افسردگى در محيطهاى شغلى نشان دادند در حالى كه درمان
مورد اثربخشى درمان شناختى - رفتارى براى افسردگى و مشكلات روان

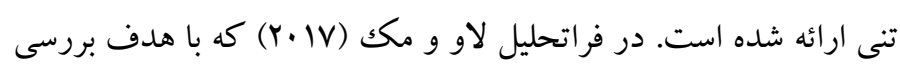
اثربخشى مداخله هاى افسردگى در محيطهاى شغلى آسيايى در 19 مطالعه

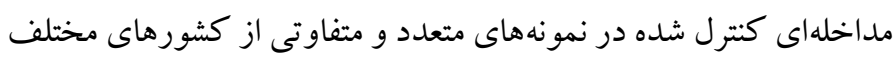

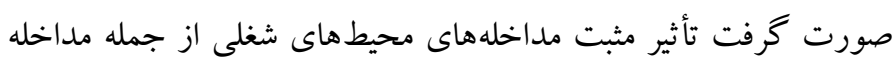

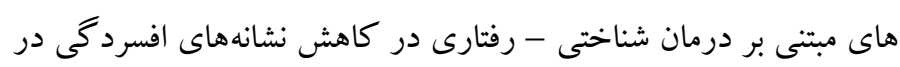

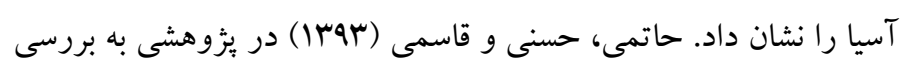

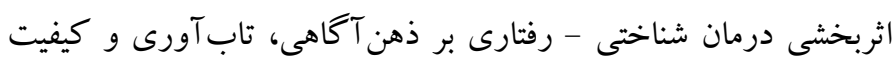

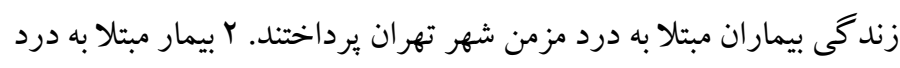

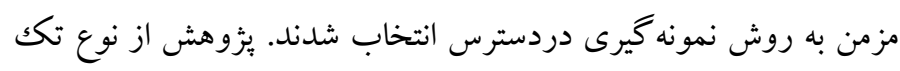

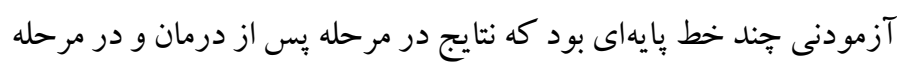

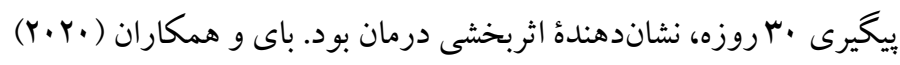

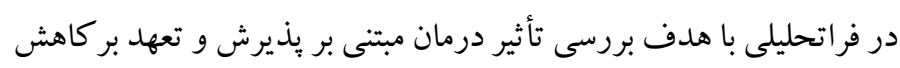

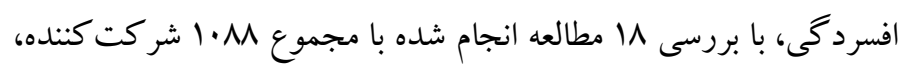

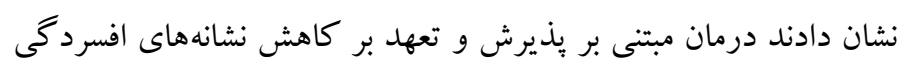
اثر مثبت معنىدارى دارد. كيانى، صباحى، مكوندحسينى، رفيعىنيا و آل -

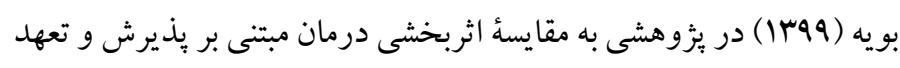

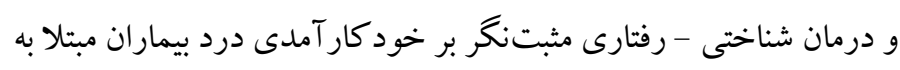

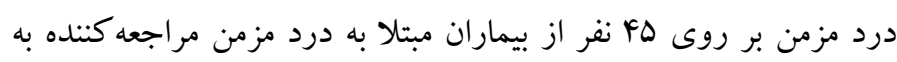

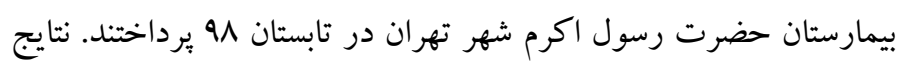
نشان داد بين درمان مبتنى بر بذيرش و تعهد و درمان شناختى - رفتارى

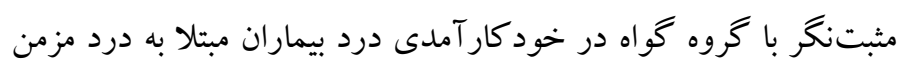

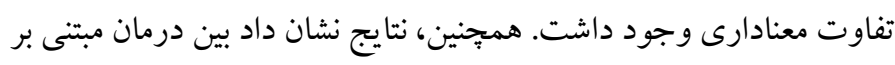

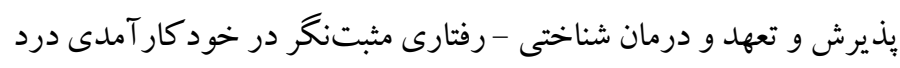

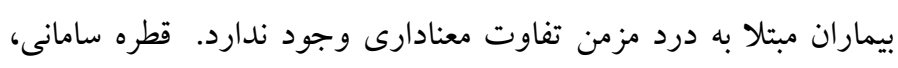

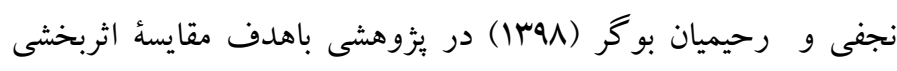

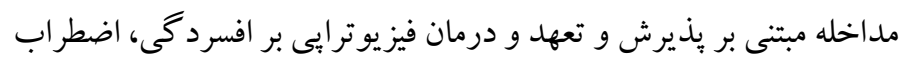

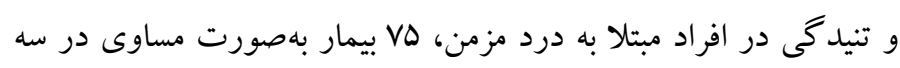

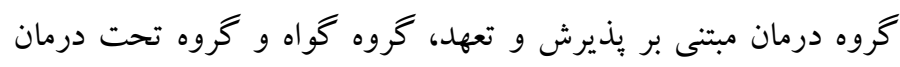

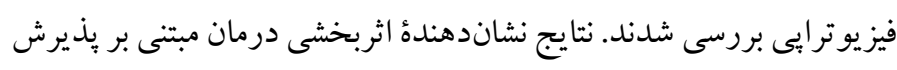

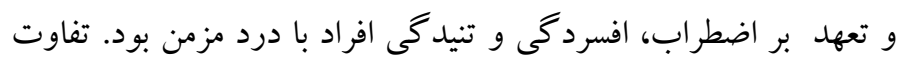

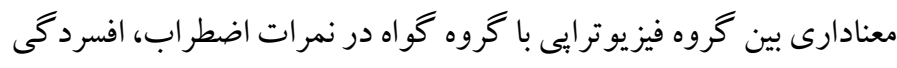


رفتار را با استفاده از فنون درمانى متفاوت دنبال مى كنند. آنكونه كه در

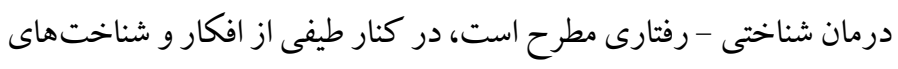

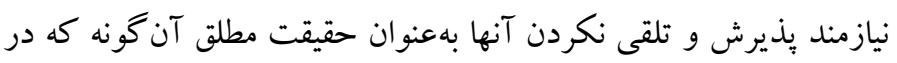

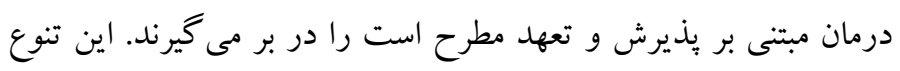

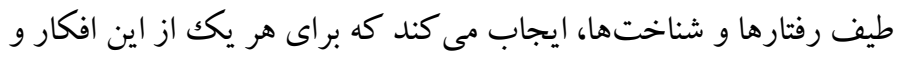

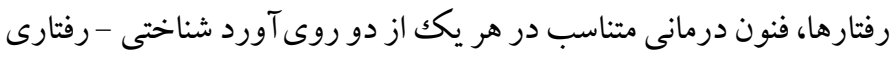

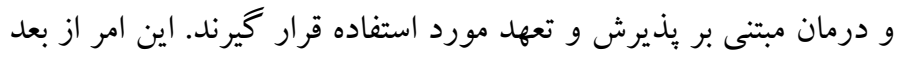

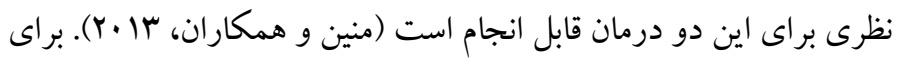

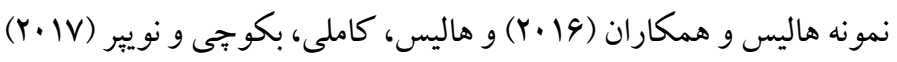
تركيب درمان شناختى - رفتارى و درمان مبتنى بر يذيرش و تعهل را براى

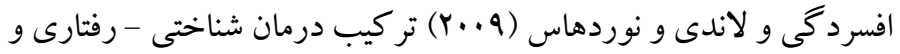
درمان مبتنى بر بذيرش و تعهد را براى درد مزمن همراه با مطرح نمودن منطق و زيربناى نظرى مربوطه مانند يُزوهش حاضر، مورد بردي استفاده قرار

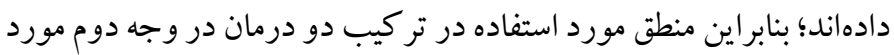
اشاره، استفاده متناسب از فنون دو درمان با طيف مشكلات شناختى، هيجانى و رفتارى آتشنشانان با نشانهاى افسردگى و مشكلات روان تهنى

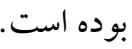

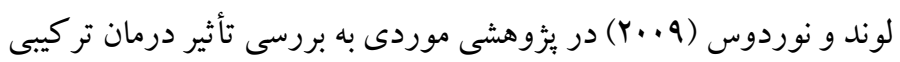

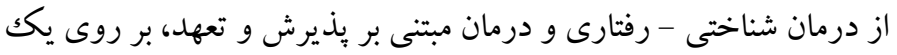
زن مسن با هشت سال سابقة درد مزمن برداختند. نتايج نشاندهندة بهبود

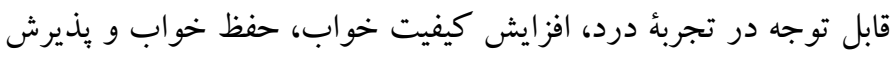

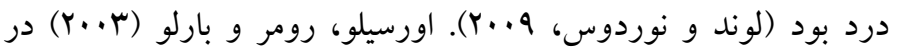

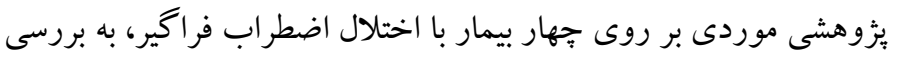
اثربخشى ادغام فنون درمان مبتنى بر بذيرش و تعهد و ذهن بـ آكاهى در درو درمان شناختى - رفتارى يرداختند. نتايج نشان داد كه بهبود قابل توجهى در سطح

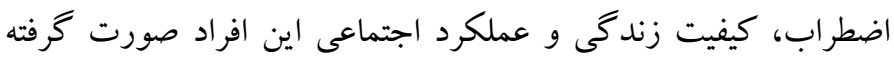

هاليس و همكاران (Y) (Y) برنامؤ درمان تر كيبى شناختى و يذيرش و تعهد را طراحى كردند كه در يثوهش حاضر اثربخشى آن مورد بررسى قرار

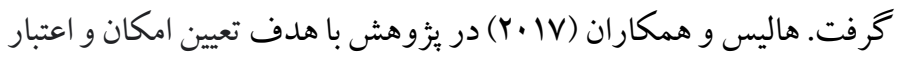

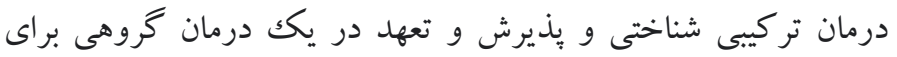

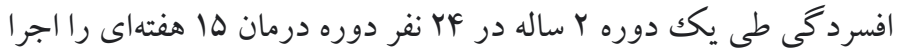

شناختى - رفتارى بيشترين استفاده را در درمان افسردگى در محيطهاى

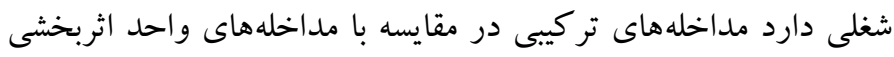

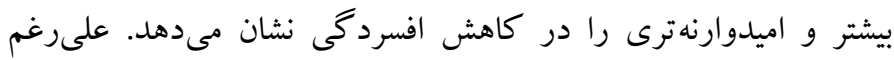

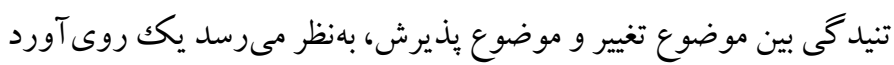

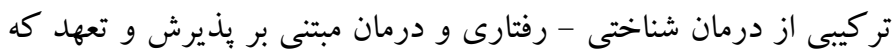

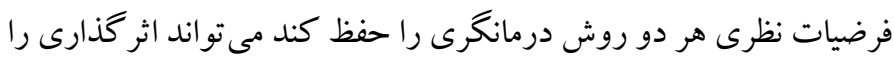

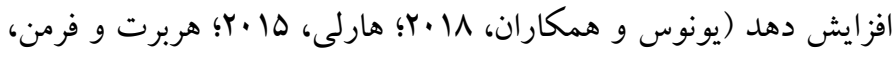

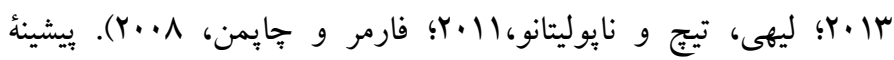

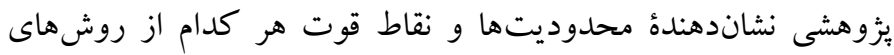

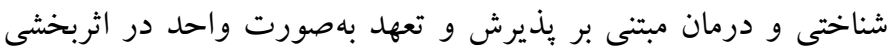

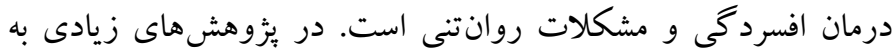
بررسى اثربخشى و مقايسٔ درمان شناختى و درمان مبتنى بر يذيرش و و تعهد

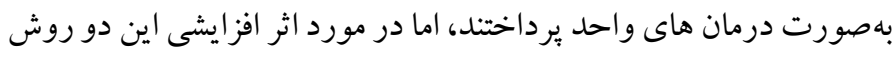

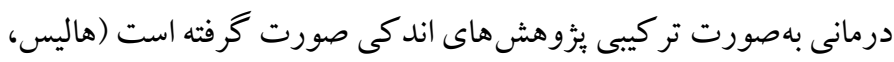

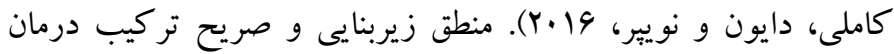

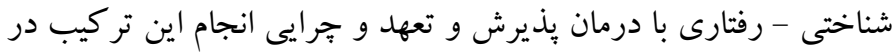

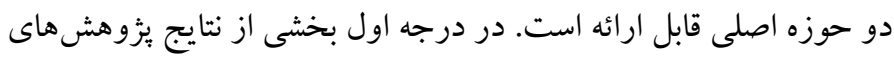

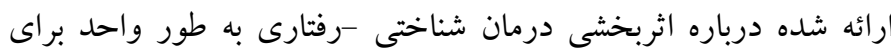

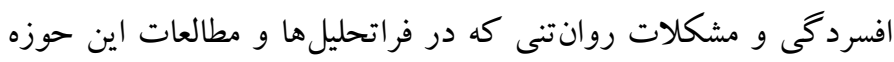

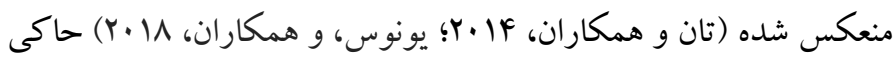
از آن است كه در برخى موارد ممكن است درمان شناختى - رفتارى به تنهايى داراى تأثيرات ضعيفى باشد. از اين منظر تر كيب فنون بازسازى و و

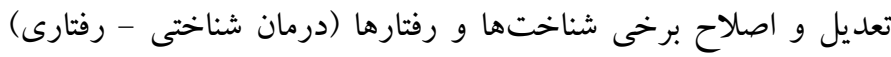

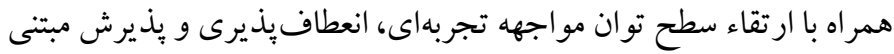

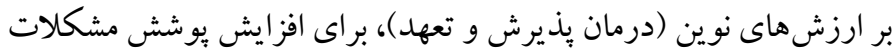

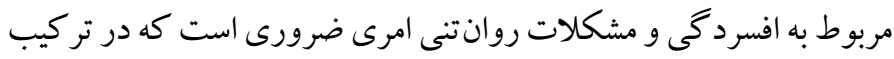
دو درمان حاصل مىشود. حوزة دومى كه مبناى استفاده تركيبى از دو درمان شناختى - رفتارى و درمان يذيرش و تعهل در اين مطالعه بوده،

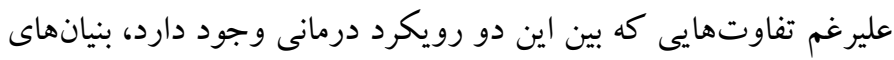

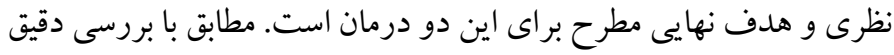

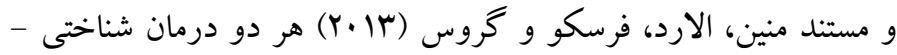
رفتارى و درمان مبتنى بر بذيرش و تعهد اهداف نهايى تغيير توجه، تفكر و وردي 
شغلى بررسى كند يافت نشد و شكاف ئزوهشى در اين زمينه وجود دارد،

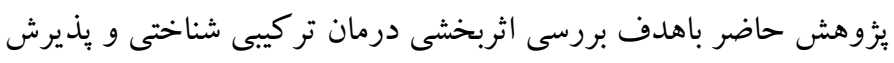

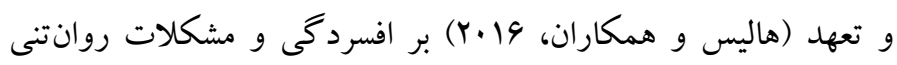

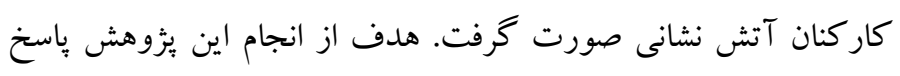

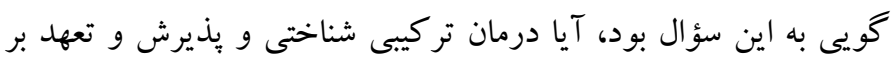

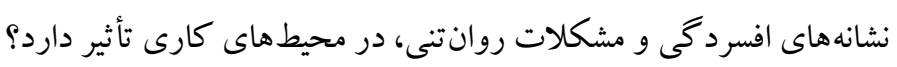

الف) طرح يثوهش و شر كت كنند كان: يزوهش حاضر از لحاظ هدف

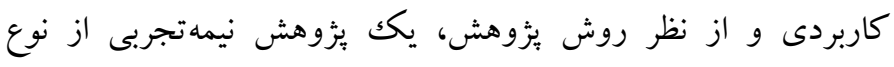

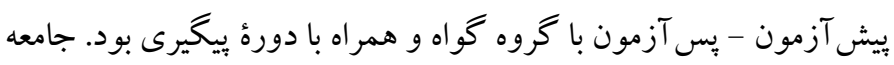

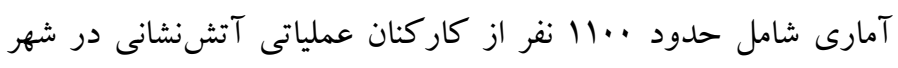
مشهد در سال V9 I بودند. بهمنظور انتخاب نمونه، در غربالخرى نخست، يرسشنامهُ سلامت عمومى اجرا شد. سيس از طريق مصاحبة تشخيصى بر

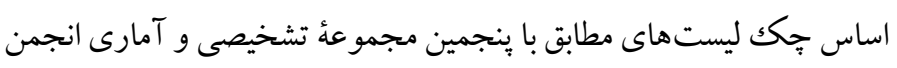

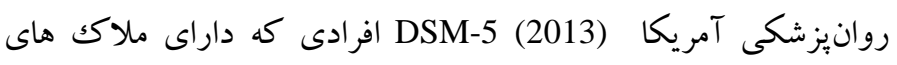
تشخيصى افسردگى و مشكلات روان تنى و ساير ملاككهاى ورود بودند

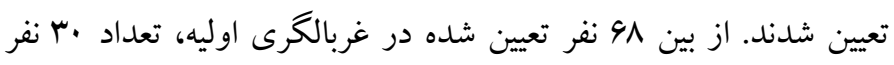
بهصورت تصادفى انتخاب شدند. بهنظور ايجاد شرايط آزمايشى لب نفر

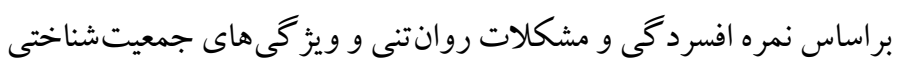

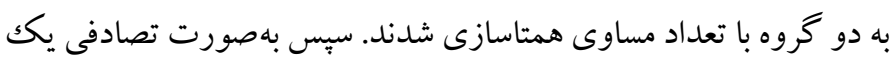

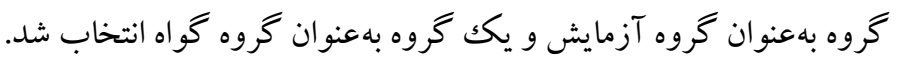
ملاككهاى ورود شركت كنند كان در بززوهش شامل: تحصيلات حداقل

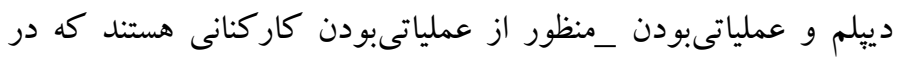

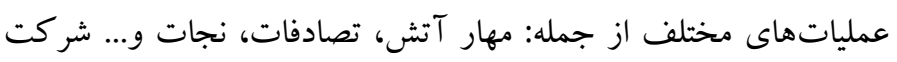

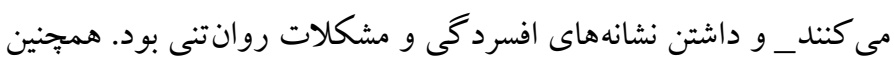

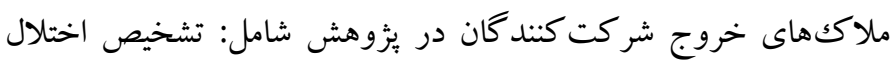

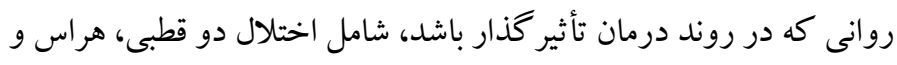

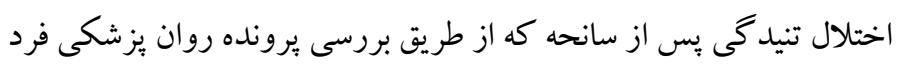
در بخش طب كار و مصاحبه تشخيصى توسط روانشناس بالينى انجام شد،

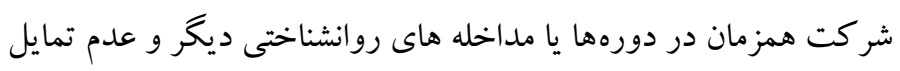

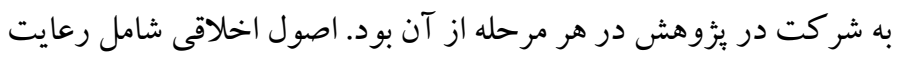

كردند. يافتها نشاندهنده رضايت از درمان، كاهش قابل توجهى در شدت

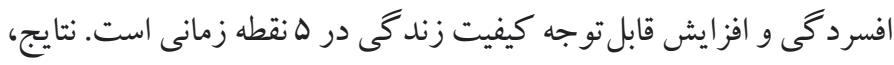

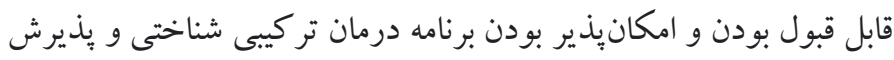

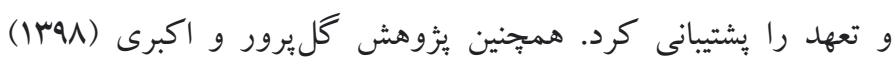

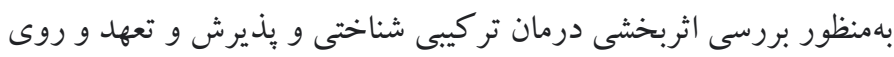

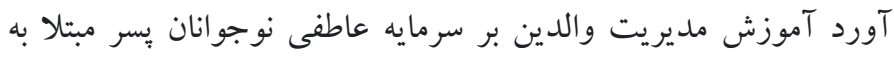

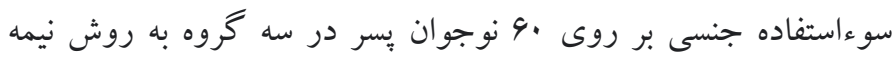

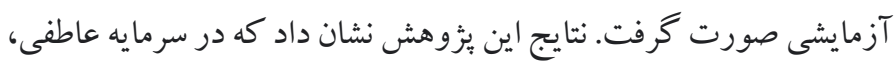

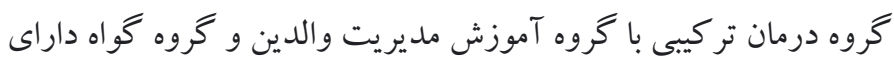

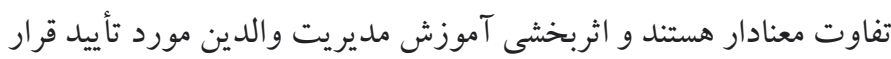

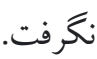

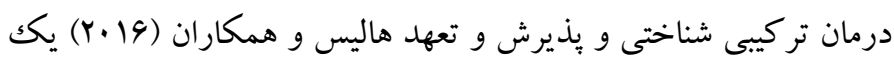

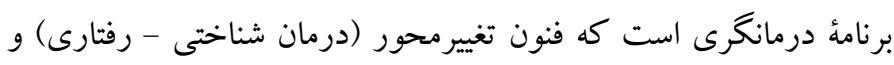

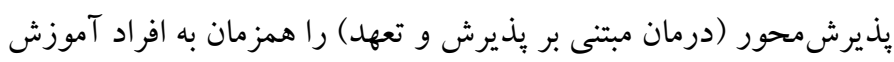

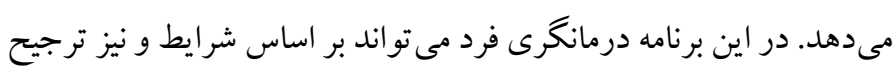

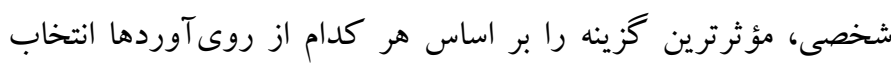

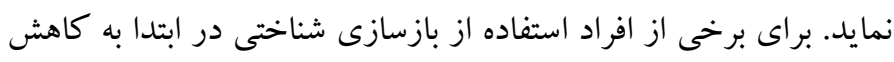

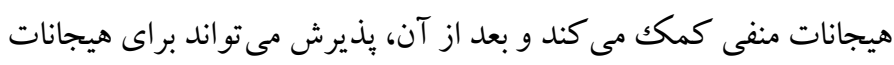

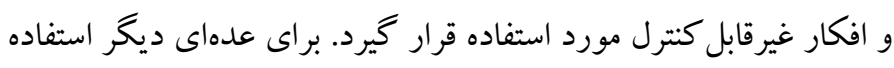

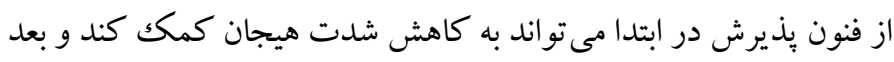

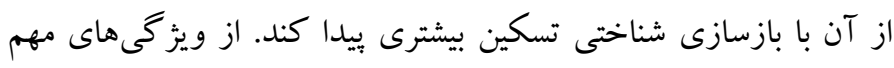

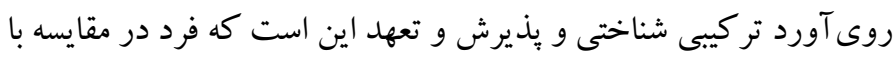

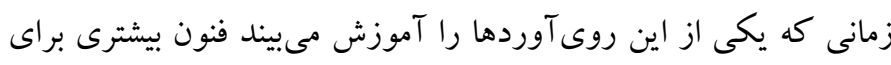

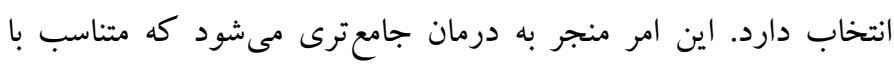

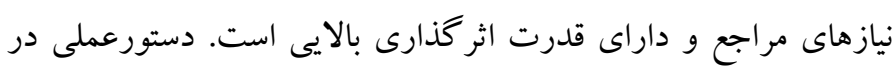
خصوص زمانها و موقعيت هايى كه بهتر است از فنون تغيير و يا فنون يذيرش استفاده شود در اختيار افراد قرار مى خيرد. در اين يُوهش درمان تر كيبى شناختى و يذيرش و تعهد هاليس و همكاران

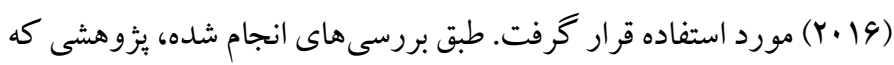

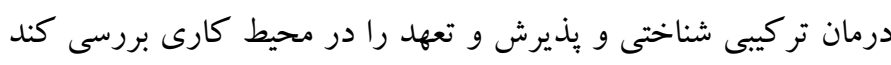

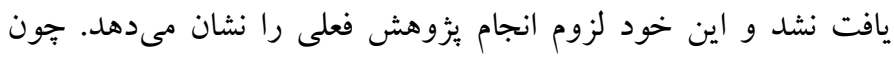

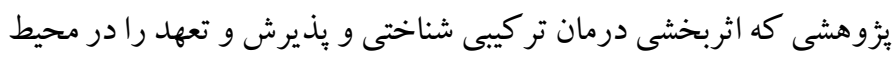


هيجوقت تا تقريبأ هر روز بِاسخ داده مى شود و طبق اين روش نمره گذارى

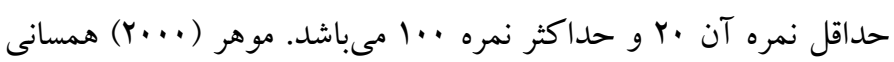

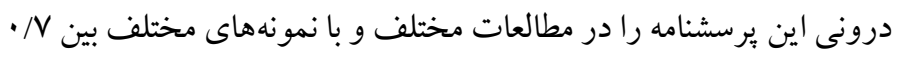

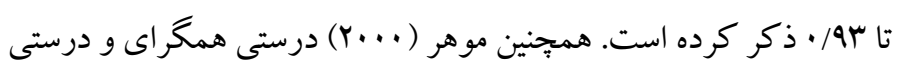

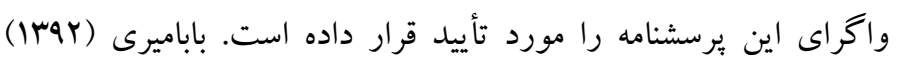

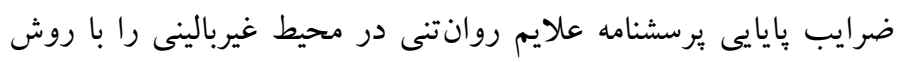

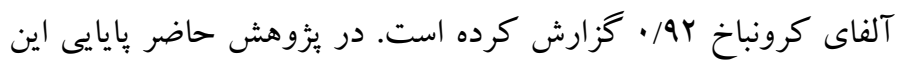

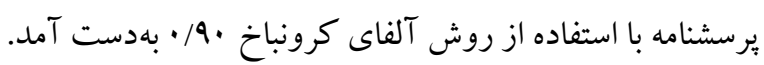

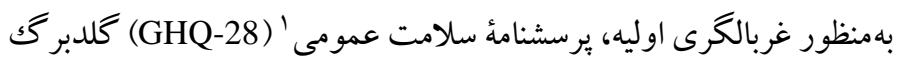

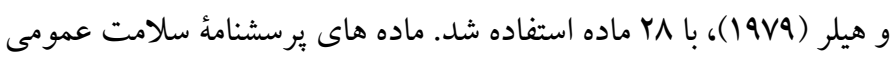

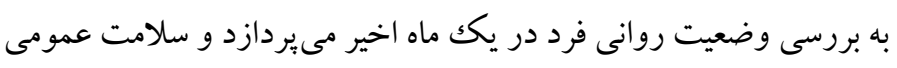

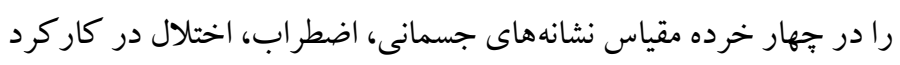
اجتماعى و علايم افسردگى بررسى مى كند (تقوى، • •دبا). روش نمره -

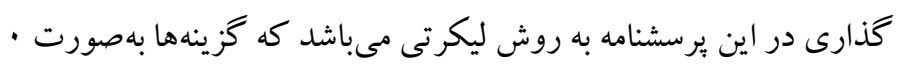

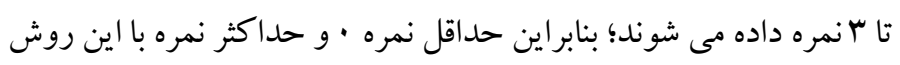

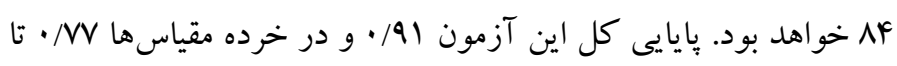

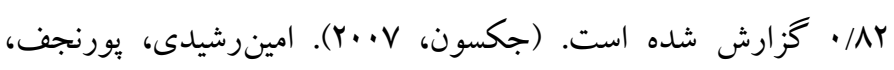

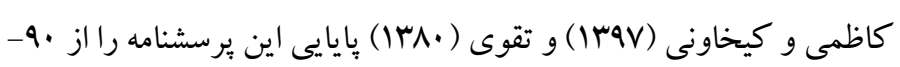

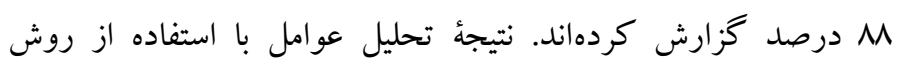
جرخشى واريماكس و بر اساس آزمون اسكرى، بيانكر وجود عوامل،

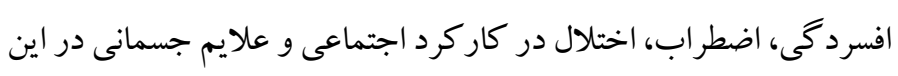
يرسشنامه است كه در مجموع بيش از •ها درصد واريانس كل آزمون را

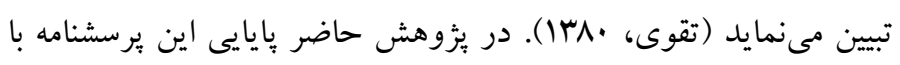

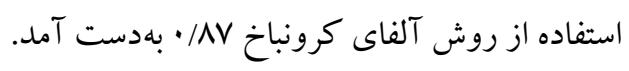
بسته درمان تركيبى شناختى و بذيرش و تعهل، توسط هاليس و همكاران

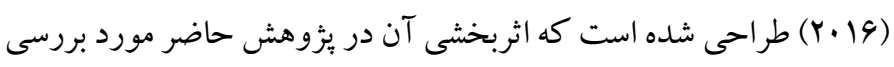

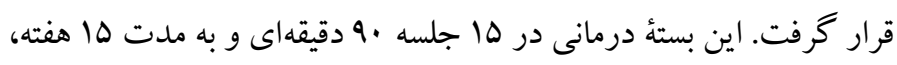

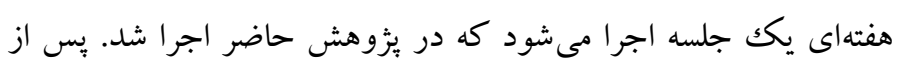

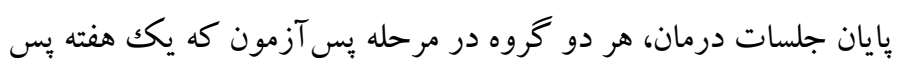

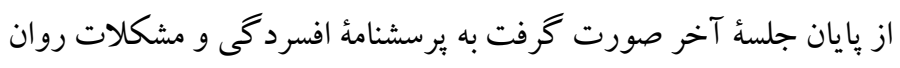

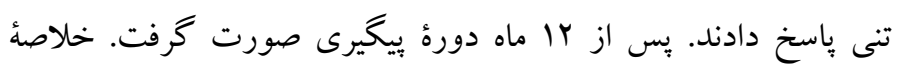

اصل رازدارى، استفاده از دادهها فقط در راستاى اهداف اين بثزوهش،

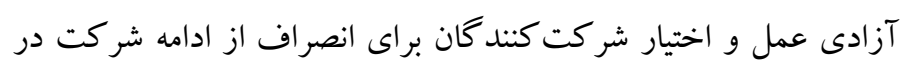

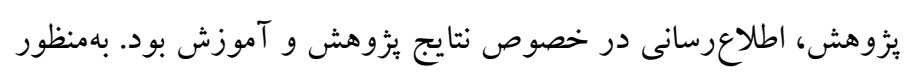

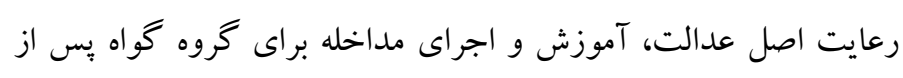
اتمام بزوهش در صورت درخواست شركت كنند كان، رعايت شدند. ب) بابزار بهمنظور سنجش متغيرهاى يزّوهش از برسشنامهاى افسردگى، مشكلات

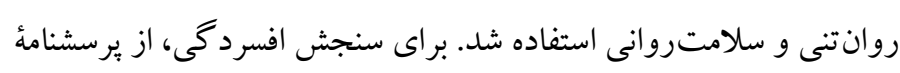

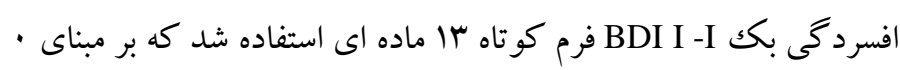

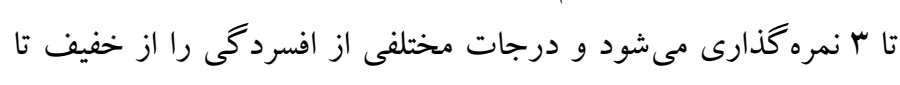

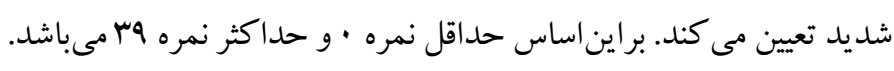
اين برسشنامه نخستين بار در سال 1991 توسط آرون بكك و همكاران تهيه

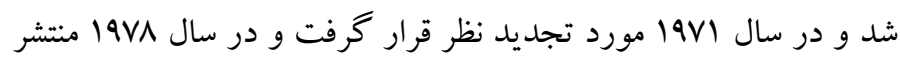

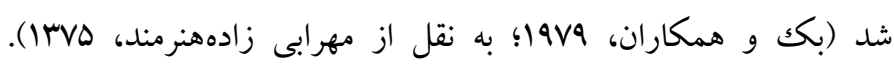

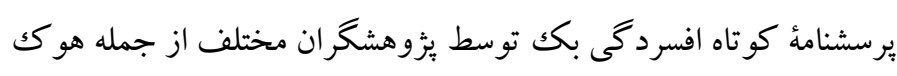

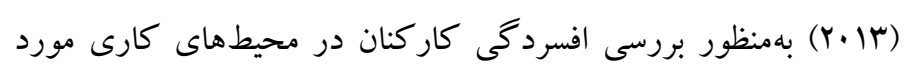

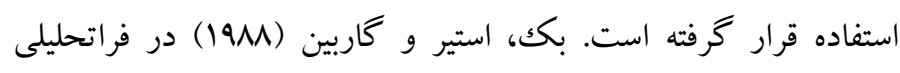

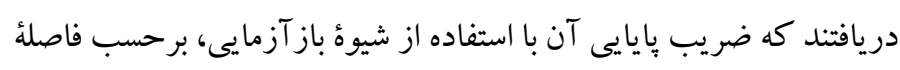

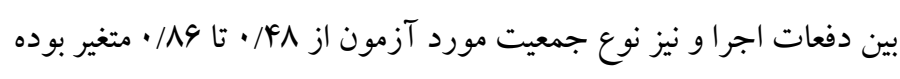

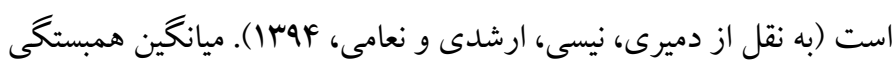

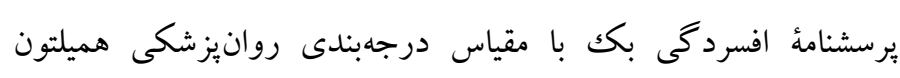

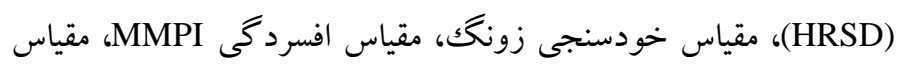

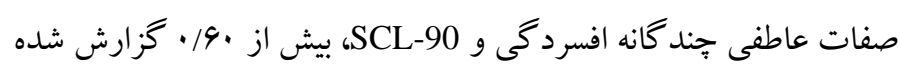

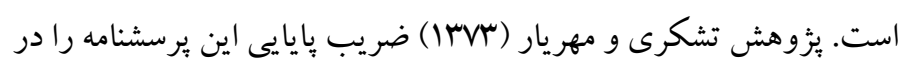

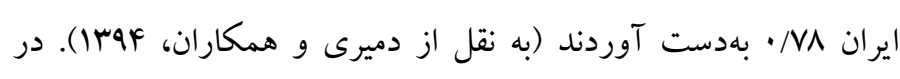

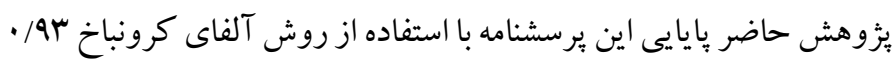
بهدست آمد. جهت سنجش مشكلات روانتنى از يرسشنامهٔ علايم روانتنى در محيط

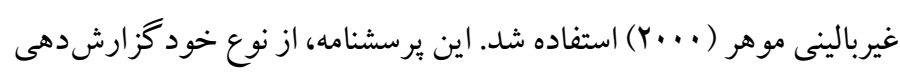
است و شدت علايم روانتنى تجربه شده توسط فرد را اندازه كيرى مى كند.

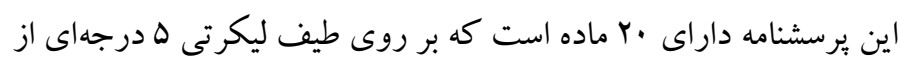

1. General Health Questionare 
دستورعملى بهمنظور راهنمايى افراد در خصوص زمانها و موقعيتهايى كه بهتر است از فنون تغيير و يا فنون يذيرش استفاده كنند در اختيار آنان قرار داده شد. در تحليل آمارى دادهها، در سطح توصيفى از ميانخين و انحراف معيار و در سطح استنباطى از تحليل واريانس اندازه گيرى مكرر استفاده شد. اين تحليل ها از طريق نرمافزار Spss نسخه ry انجام شد.
محتو اى جلسات درمان تركيبى شناختى و يذيرش و تعهد در جدول ا ارائه شده است. ساختار درمان به اين صورت است كه به آزمودنىهاى كروه آزمايش در سراسر درمان ياد آورى مىشود كه با دو روى آورد درمانكرى مختلف آشنا مىشوند و دو الكوى درمانكرى به گونهاى برابر مفيد هستند و آنان از يادگيرى فنون مختلف بيشتر سود خواهند برد. همجينين

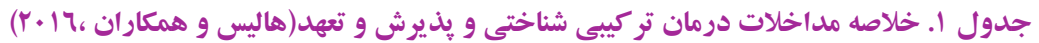

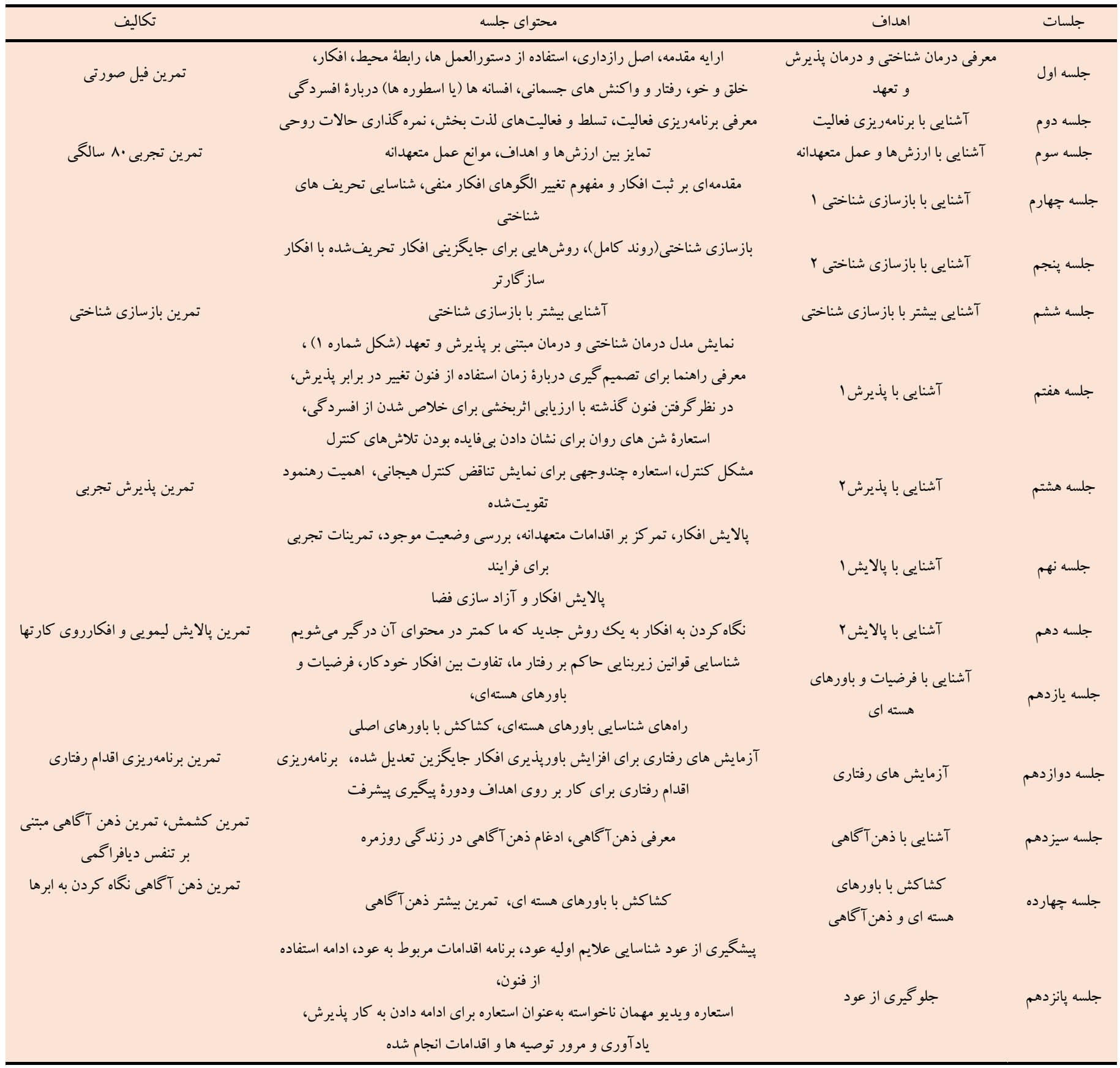


دييلم، 9 نفر لي سانس و ا نفر فوق ليسانس بودند. آزمون مورد نظر در سه

يافته ها

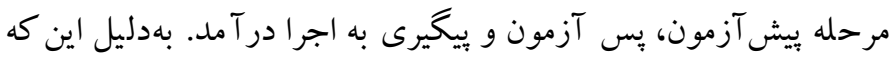

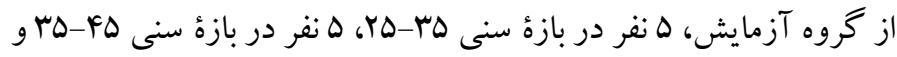

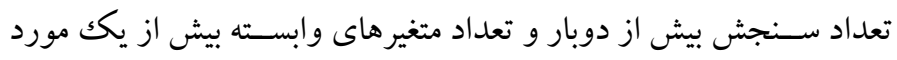

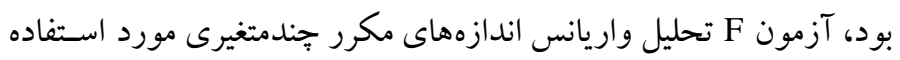

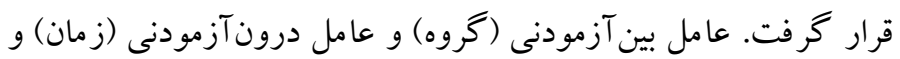
اثرتقاطعى (زمان × گروه) بدين وسيله قابل بررسى است.

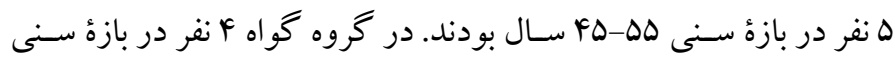
هr-Drا، ه نفر در بازٔ سنى

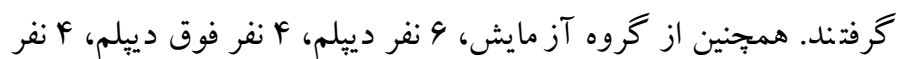

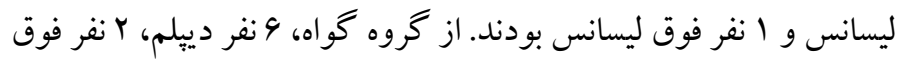

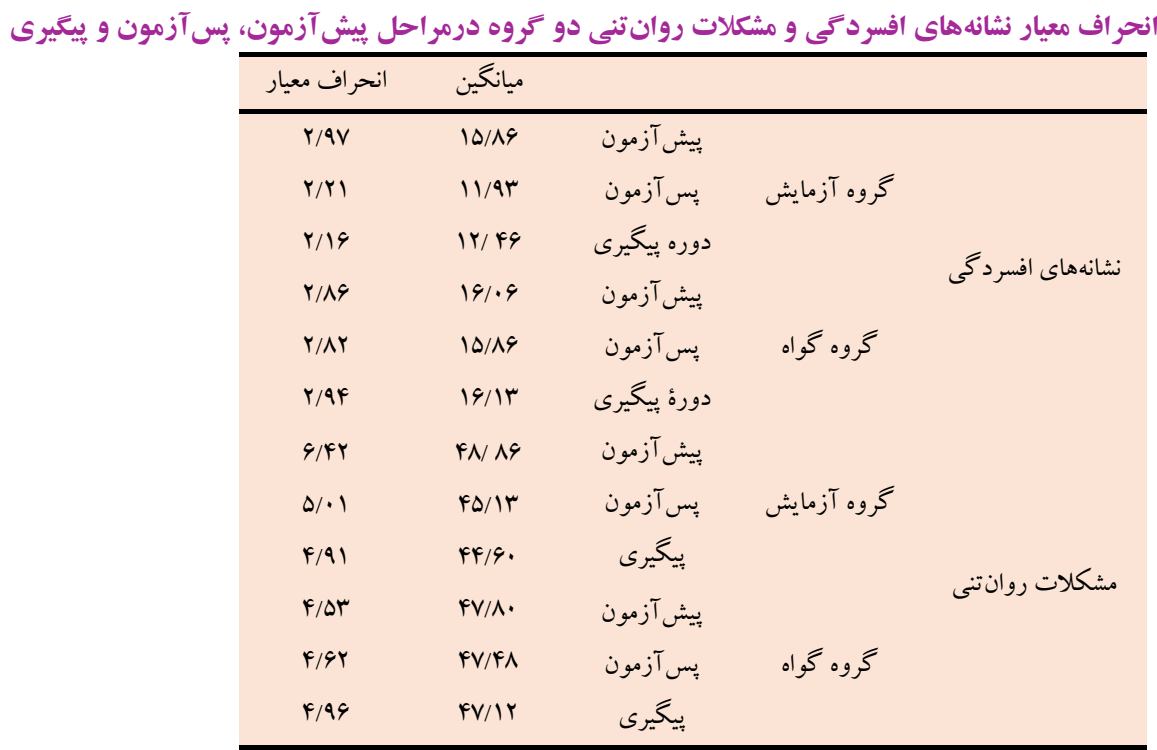

بررسى شد كه نشان داد اين مفروضه براى مؤلفههاى مورد بررسى برقرار

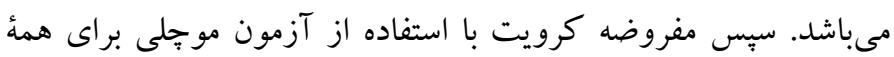

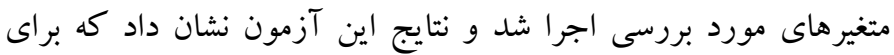

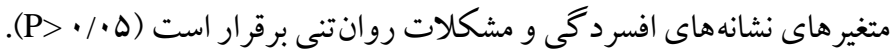

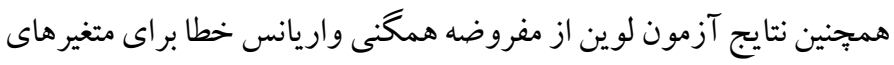

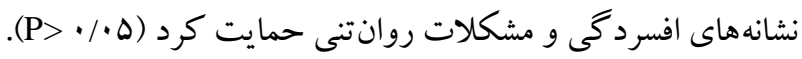
نتايج آزمونهاى جندمتغيرى در جدول س نشان مىدهد كه درمان تر كيبى

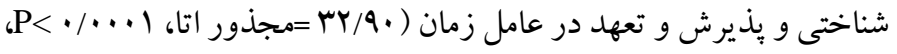

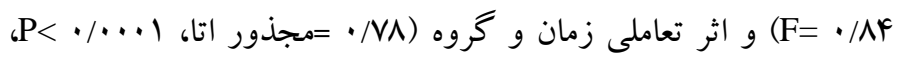
معنى (F= rY/VD شناختى و يذيرش و تعهد مورد بررسى اثربخش مىباشد.
نتايج جدول r نشان داد كه در گروه گو اه بين ميانگين نمرات ييش آزمون،

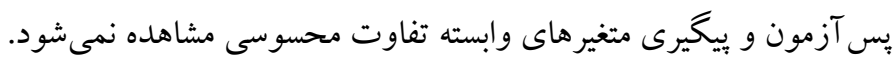

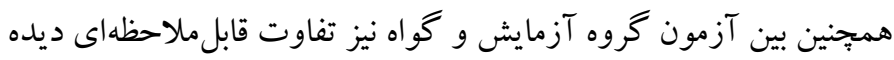

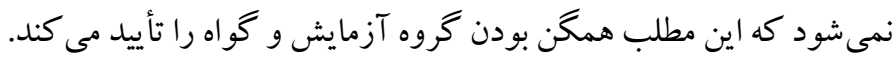

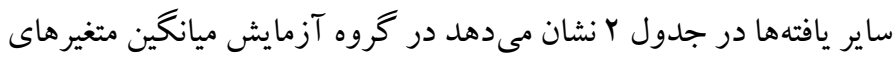

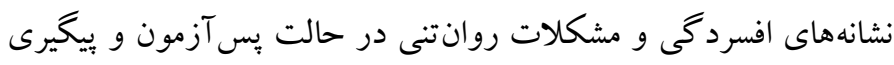

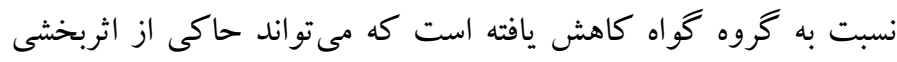
درمان تر كيبى باشد. قبل از بررسى فرضيههاى يُزوهش ابتدا دادههاى

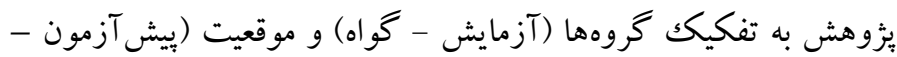
بس آزمون - بيگيرى) از لحاظ نرمال بودن دادهها با استفاده از آزمون

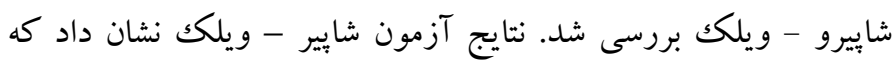

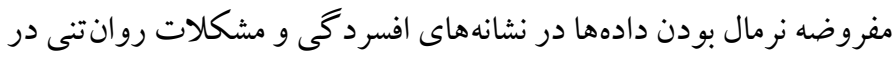

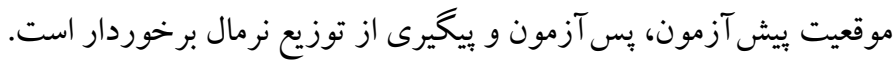

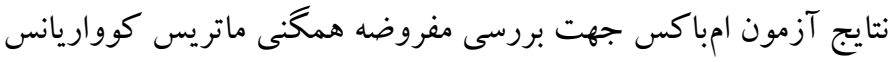




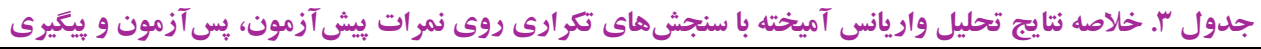

\begin{tabular}{|c|c|c|c|c|c|c|c|c|}
\hline اندازه اثر & سطح معنى دارى & خطbا DF & DF & $\mathrm{F}$ & مقدار & آزمون & & شاخ \\
\hline$\cdot / r \mid$ &.$/ .4 \Lambda$ & rV & r & $r / 99$ & $\cdot / r 1$ & اثر بيلايى & \multirow{4}{*}{ گروه } & \multirow{4}{*}{ بين گروهى } \\
\hline$\cdot / Y 1$ & . & rV & r & $r / 99$ & $\cdot / \mathrm{VA}$ & لامبداى ويلكز & & \\
\hline$\cdot / Y 1$ & $\cdot / \mu_{\Lambda}$ & rV & r & $r / 99$ & $\cdot / T V$ & اثر هتلينگك & & \\
\hline$\cdot / Y I$ & . . r & rV & r & $r / 99$ & $\cdot / T V$ & بزر گترين ريشه روى & & \\
\hline - /AF & $\cdot / \cdots 1$ & ro & f & $r_{r / q}$. & - /AF & اثر بيلايى & \multirow{5}{*}{ زمان } & \multirow{8}{*}{ درونگروهى } \\
\hline - /AF & $\cdot / \cdots 1$ & ro & f & $r r / q$. &.$/ 19$ & لامبداى ويلكز & & \\
\hline - /AF & $\cdot / \cdots, 1$ & ro & r & $r_{T / q}$. & $\Delta / r \varphi$ & اثر هتلينگ & & \\
\hline$\cdot / A F$ & $\cdot / \cdots \cdot 1$ & ro & r & $r r / q$. & $\Delta / r^{\prime}$ & بزر گترين ريشه روى & & \\
\hline$\cdot / \mathrm{VA}$ & $\cdot / \cdots 1$ & ro & f & Yr/VQ & $\cdot / \mathrm{VA}$ & اثر ييلايى & & \\
\hline$\cdot / \mathrm{VA}$ & $\cdot / \cdots 1$ & ro & f & Yr/VQ & $\cdot / r)$ & لامبداى ويلكز & \multirow{3}{*}{ زمانش گروه } & \\
\hline$\cdot / \mathrm{NA}$ & $\cdot / \cdots 1$ & ro & f & Yr/VQ & $r / 94$ & اثر هتلينگك & & \\
\hline$\cdot / \mathrm{VA}$ & $\cdot / \cdots 1$ & ro & f & YY/VQ & $r / 94$ & بزر گترين ريشه روى & & \\
\hline
\end{tabular}

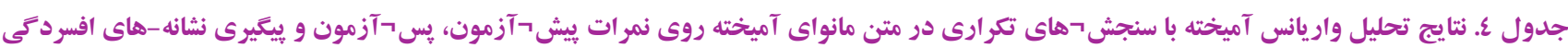

\begin{tabular}{|c|c|c|c|c|c|c|c|c|}
\hline توان آمارى & اندازه اثر & سطح معنىدارى & $F$ & مجذيانگين & آزادى & مجذورات & متغيرهاى وابسته & شاخص \\
\hline$\cdot / \mathrm{V} 9$ & $\cdot / \times 10$ &.$/ \cdot 1$ & $V / 94$ & $10 Y / 1$. & 1 & $10 r / 1$. & نشانه هاى افسردگى & بين آزمودنى (كروه) \\
\hline 1 & $\cdot / \Delta \Lambda$ & $\cdot 1 \cdots \cdot$ & $\pi / 99$ & $\mathrm{rq1.4}$ & r & $V Y / \cdot \Lambda$ & نشانههاى افسردگى & 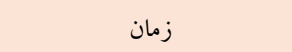 \\
\hline 1 & $\cdot 109$ & $\cdot / \cdots 1$ & ra/Ar & rT/QT & r & $98 / .9$ & نشانه هاى افسردگى & درون آزمودنى (زمان × گروه) \\
\hline
\end{tabular}

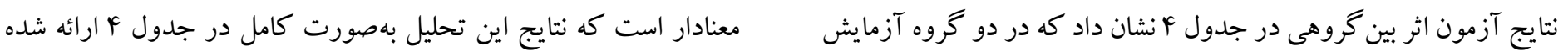

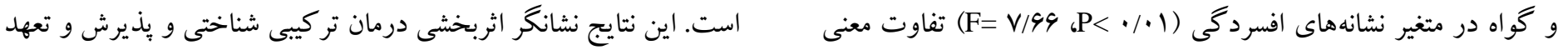

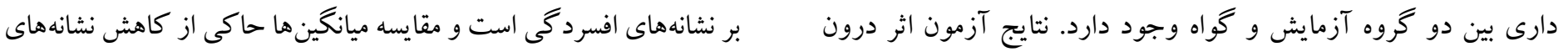

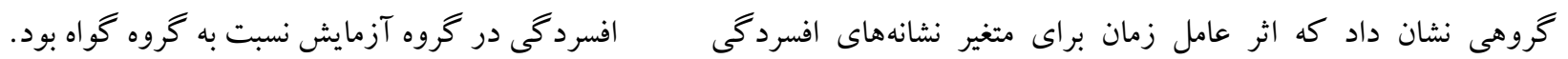

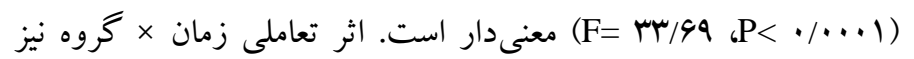

\begin{tabular}{cccccccc}
\hline \\
\hline
\end{tabular}

معنادار است كه نتايج اين تحليل در جدول ه ارائه شده است. اين نتايج نشانگر اثربخشى درمان تركيبى شناختى و بذيرش و تعهد بر مشكلات

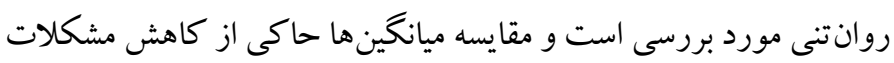

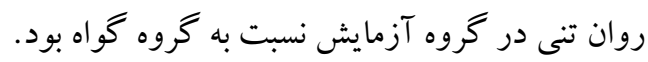

همجينين نتايج آزمون اثر بين گروهى در جدول ها نشان داد كه در دو گروه

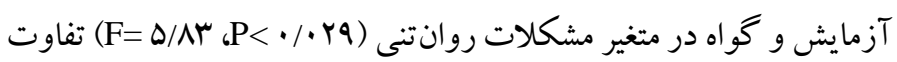
معنى دارى بين دو گروه آزمايش و گواه وجود دارد. نتايج آزمون اثر داني

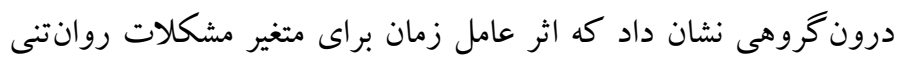

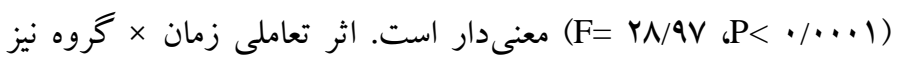




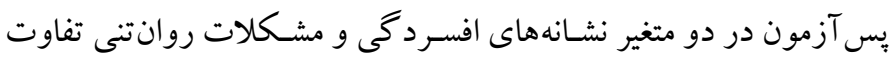

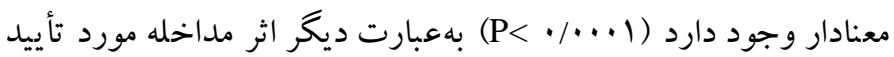
قرار مى گيرد.
يُ از اين كه اثرات زمان، گروهو و تعاملى معنادار شـــد در ادامه به كمكك

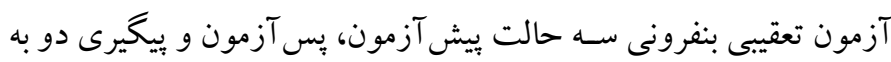

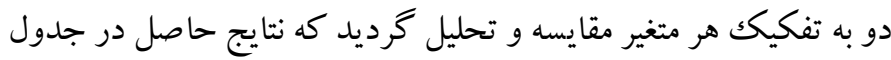

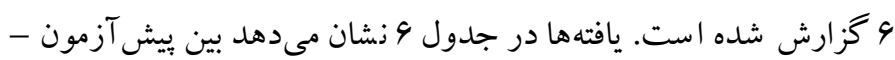

جدول 7. نتايج آزمون بونفرونى براى مقايسه نمرات بيش آزمون، پِ آزمون و يِيَيرى

\begin{tabular}{|c|c|c|c|c|c|c|}
\hline حد بالا & حد بايين & سطح معنىدارى & خطاى استاندارد & اختلاف ميانگين & مقايسه & متغير هاى وابسته \\
\hline$r / 9 V$ & $1 / 49$ & $\cdot / \cdots \cdot 1$ & $\cdot / r$ & $r / \cdot 9$ & ييش آزمون - يس آزمون & \\
\hline 年 & $-\cdot / 94$ & $\cdot / 19$ & $\cdot / r$ & $-\cdot / 4$. & يس آزمون - يِيحيرى & نشانههاى افسردگى \\
\hline$r / r q$ & . /94 & $\cdot / \cdots 1$ & $\cdot / Y \wedge$ & $1 / 99$ & يِيش آزمون - يِيخيرى & \\
\hline$r / .9$ & $\cdot / 91$ & $\cdot / \cdots 1$ & $\cdot / 4$. & $r / \cdot r$ & يِش آزمون - يِ آزمون & \\
\hline$\cdot / 9 r$ & $-\cdot / \cdot r$ & $\cdot / \cdot v$ & $\cdot / 19$ & $\cdot / 4 \Delta$ & يس آزمون - يِيحيرى & مشكلات روانتنى \\
\hline$r / 4 \Lambda$ & $1 / 49$ & $\cdot / \cdots 1$ & $\cdot / r q$ & $r / F V$ & ييش آزمون - ييخيرى & \\
\hline
\end{tabular}

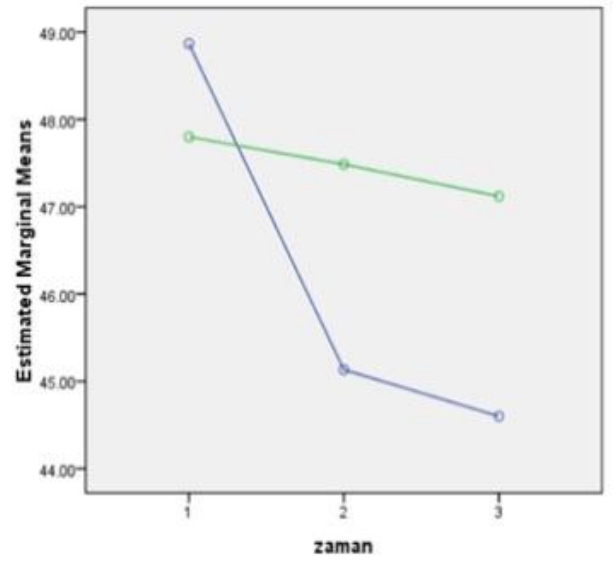

بحث و نتيجه تيرى

هدف ئزوهش حاضر بررسى اثربخشى درمان تركيبى شناختى و يذيرش و و

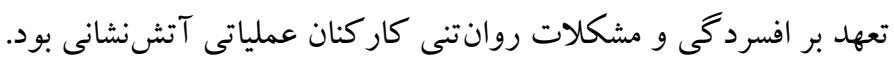

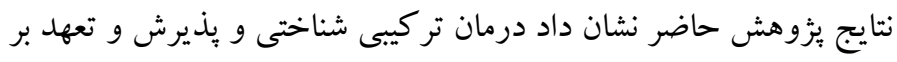

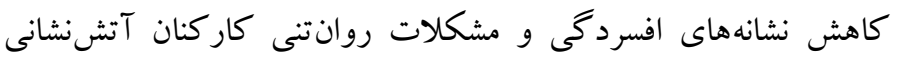

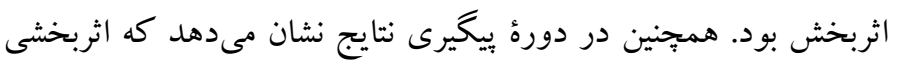

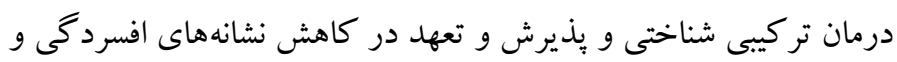

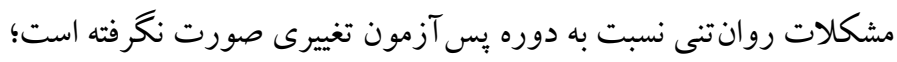

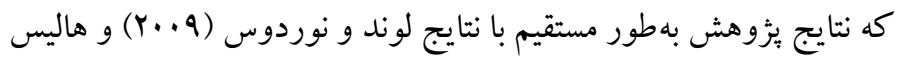

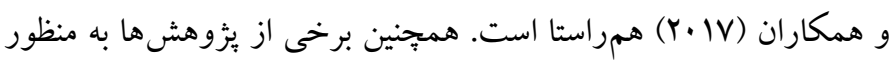
بررسى اثربخشى درمان شناختى و درمان مبتى بر يذيرش و تعهد بهصورت

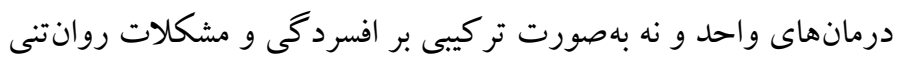

همجنين بين ييش آزمون - يِيخيرى نيز در دو متغير تفاوت معنادار وجود

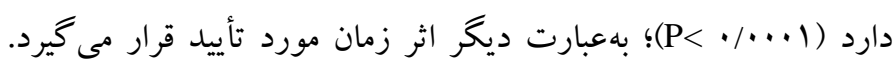

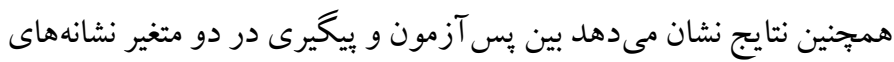

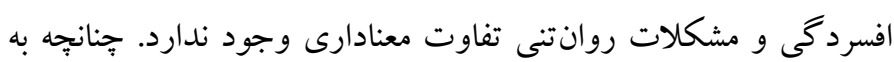

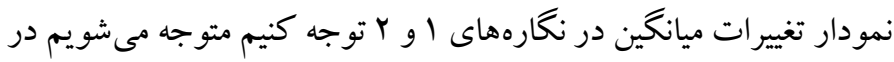

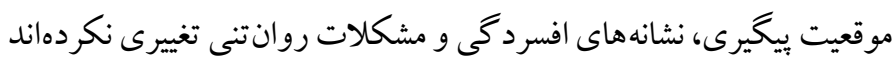

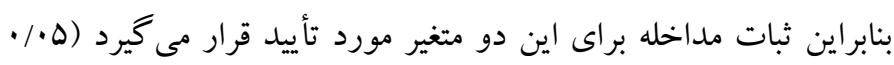

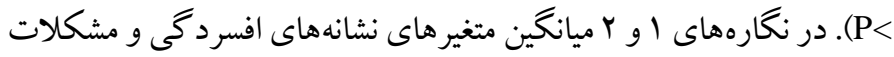
روانتنى به صورت نمودار ترسيم شده است.

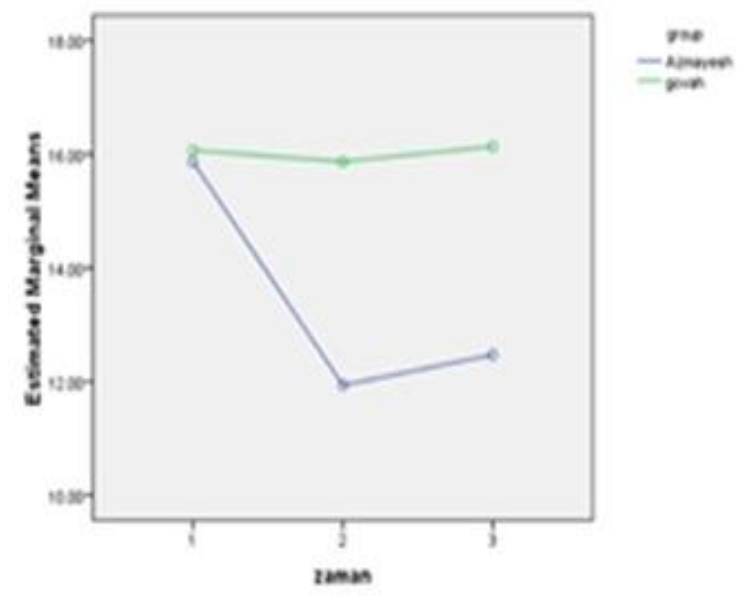


محورىترين مسيرهاى درمانى كار بر روى افزايش انعطافيذيرى و

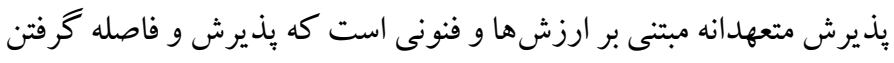

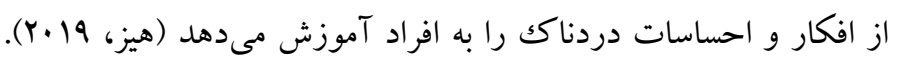
شو د. درمان تر كيبى شامل هم درمان شناختى و هم درمان مبتنى بر يذيرش

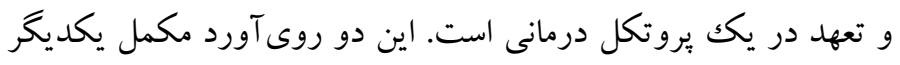

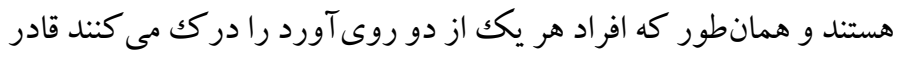
خواهند بود كه تصميم بخيرند جه زمانى از فنون تغيير (بهعنوان مثال،

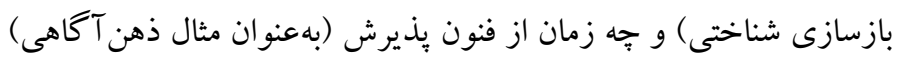

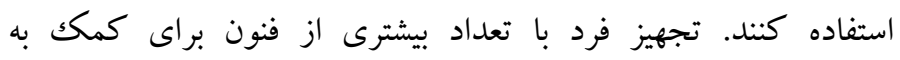

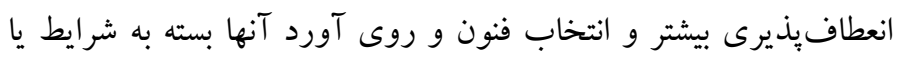

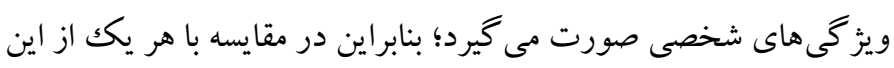

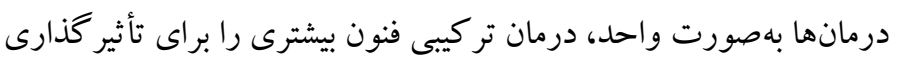

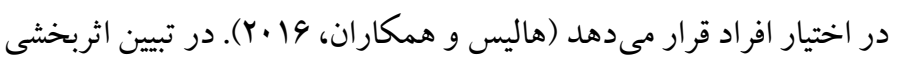

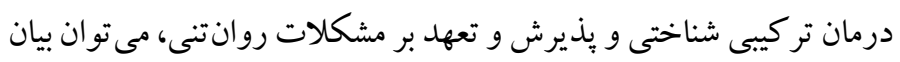

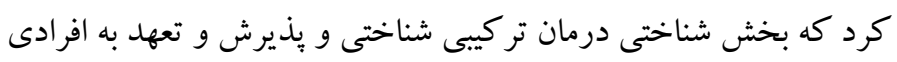
كه قادر به كشاكش با افكار و باورهاى غيرمنطقى خود هستند كمك دئك

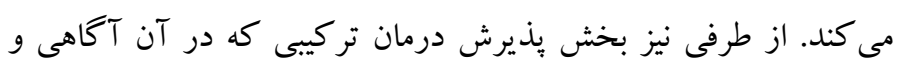
بذيرش بدن مهم است بخصوص براى افرادى كه قادر به كشاكش با بافكار

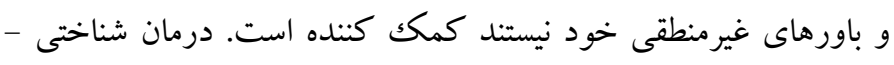

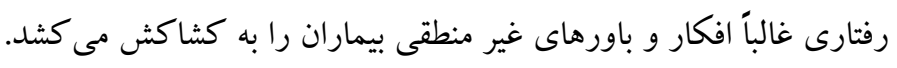

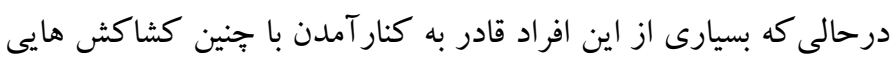

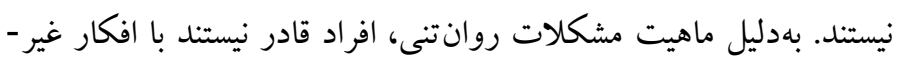

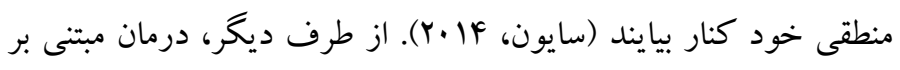

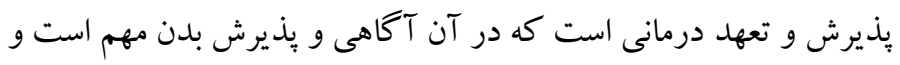

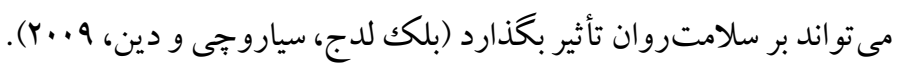

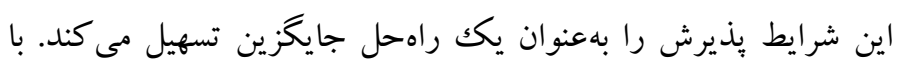

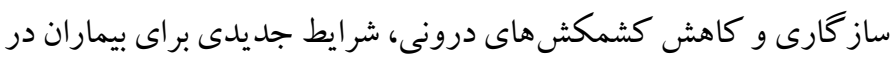
جهت بحث در مورد زندكى ارزشمند آنها ايجاد مى شود و اين امر توجه

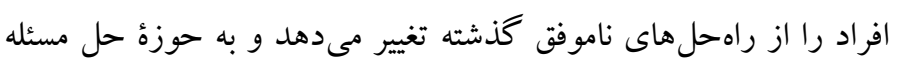

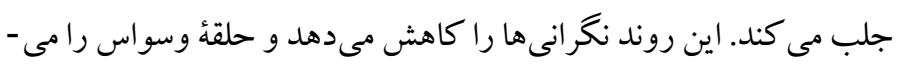

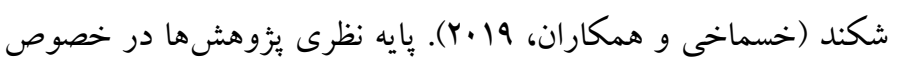

در محيطهاى شغلى به كار رفتهاند كه نتايج آن بهصورت غيرمستقيم با يافتهاى يزوهش حاضر همسو است. ازجمله در يزٔوهش باى و همكاران

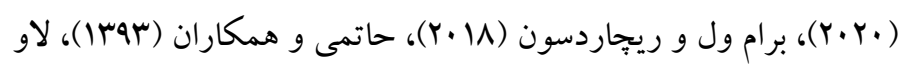

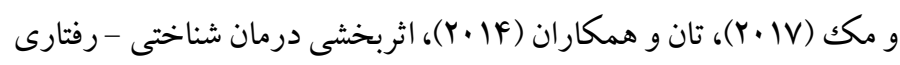

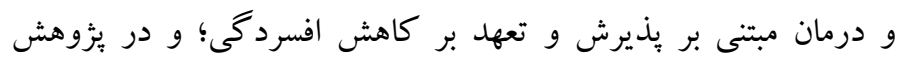

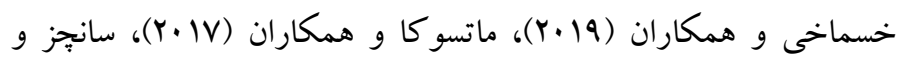

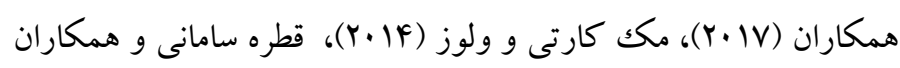

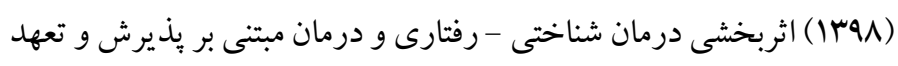
بر كاهش مشكلات روان تنى نشان داده شده است.

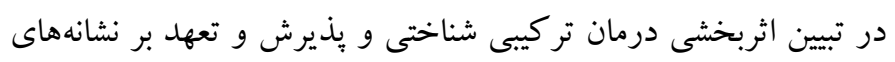
افسردگى بايد گفت، از آنجا كه كار كنان عملياتى آتش نشانى بايستى قادر

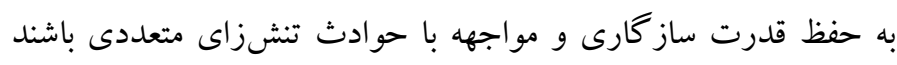

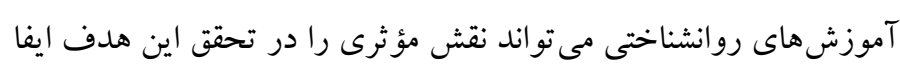
كند؛ بهخصوص درمان تركيبى شناختى و يذيرش و تعهد كه فنون متعددى مونى

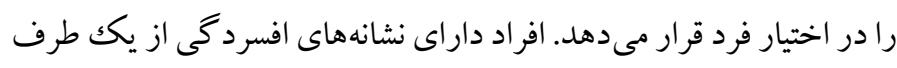

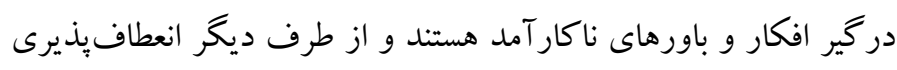

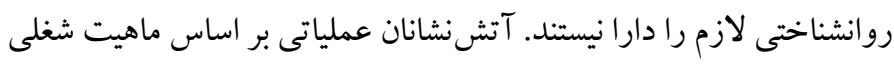

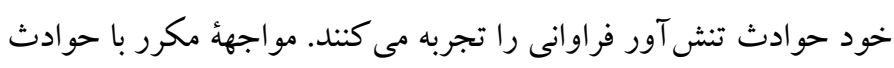

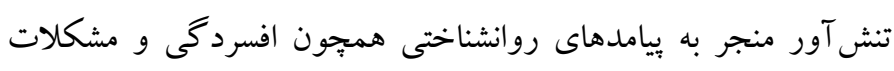

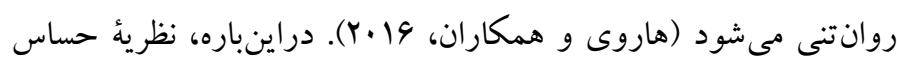

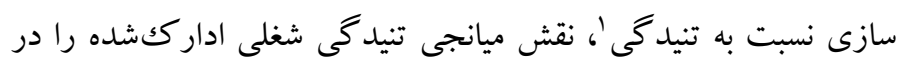

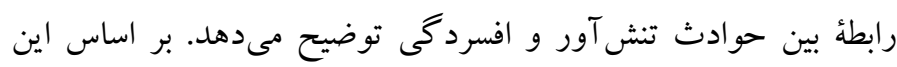
نظريه، تجربه حوادث تنش آور حساسيت فرد رابه تنيدگى افزايش مى مدهد وند

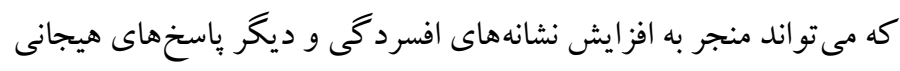

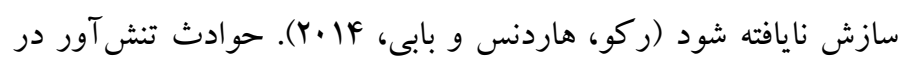

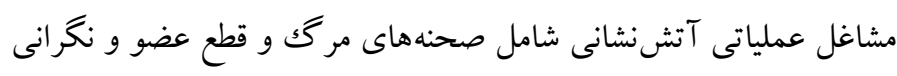
از اشتباه كردن در انجام وظايف شغلى و غيره مى شود (بيتون و همكاران،

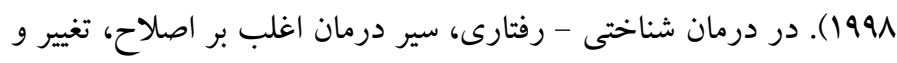

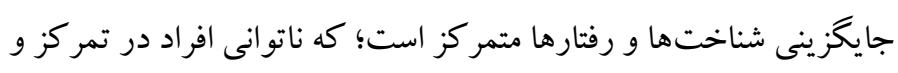
كشاكث با افكار و نشخوارهاى ذهنى منفى، درمان شناختى - رفتارى را با

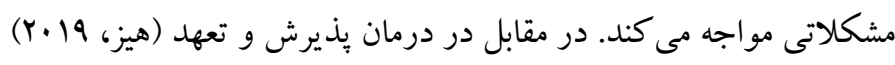

${ }^{1}$. stress sensitization theory 
مقايسه بين يافتهاى اين بثزوهش با ساير يافتها در ديخر سازمانها منجر به

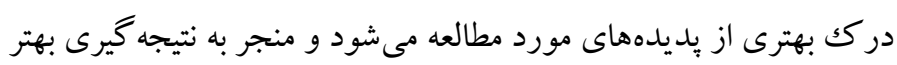

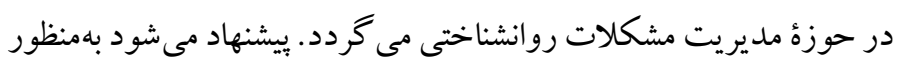

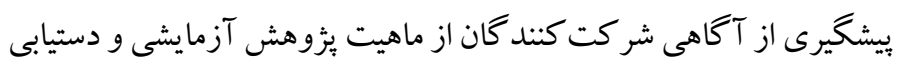

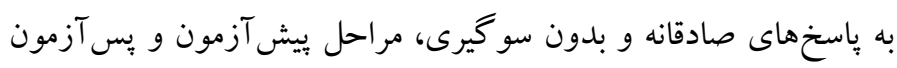

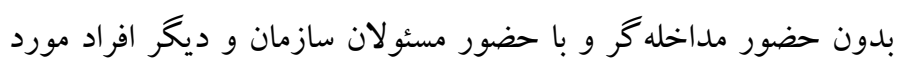

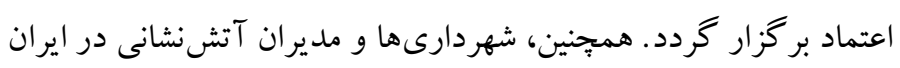

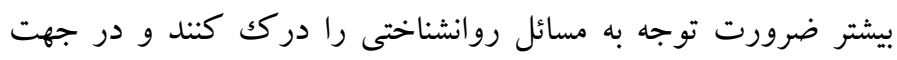

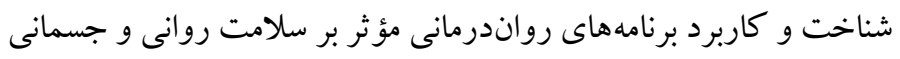

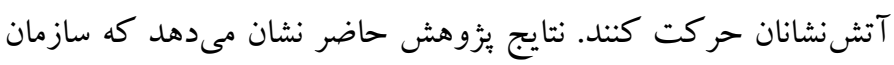
آتشنشانى مى تواند اين برنامه درمانى را بهعنوان يكك برنامه مؤثر مورد

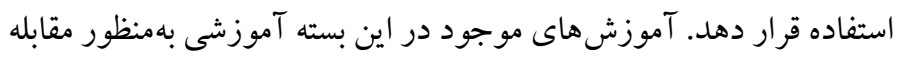
با افسردگى و مشكلات روانتنى و تنش آورهاى شغلى و باز گشت به كار

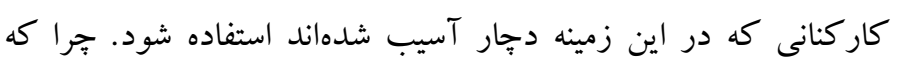

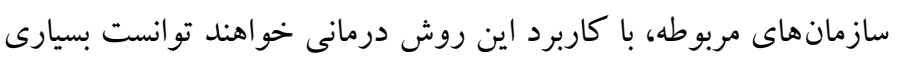

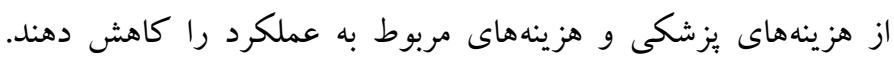

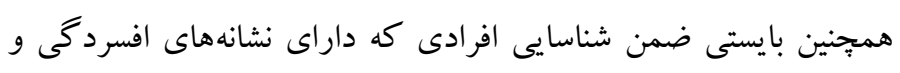

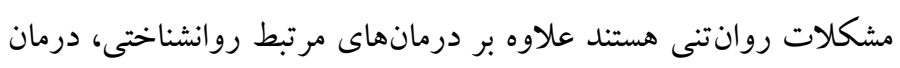

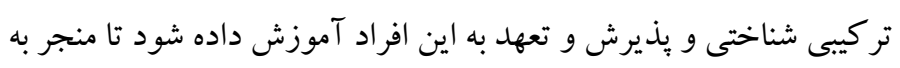

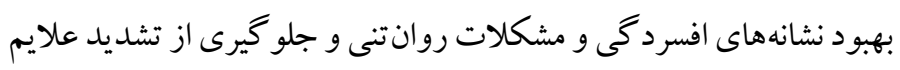

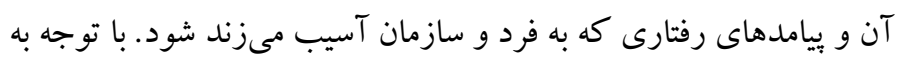

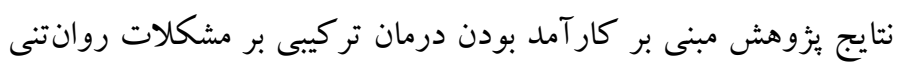
بيشنهاد مىشود بخش بز شكى (طب صنعتى) و اورزانس هاى سازمانى اولاً

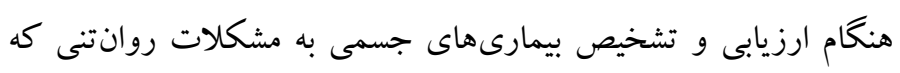

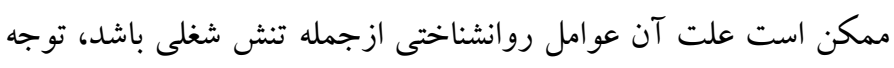

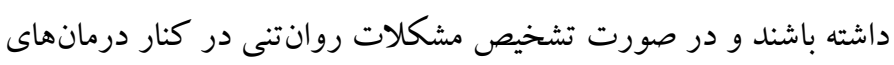

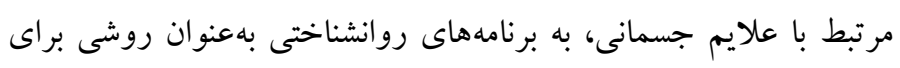

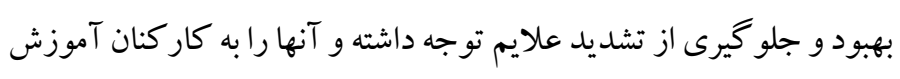
دهند. در صورت امكان آموزش مهارتهاى شناختى و يذيرش در درئ درمان

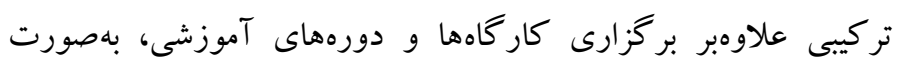

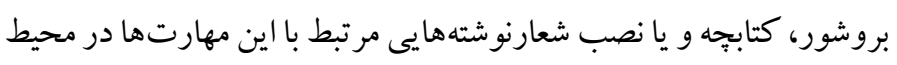

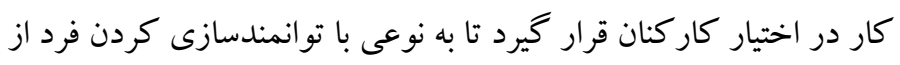

عوامل تنش آور شغلى بهعنوان يِيشبينهاى بروز مشكلات روانتنى،

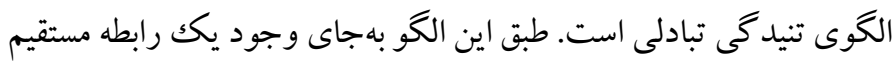

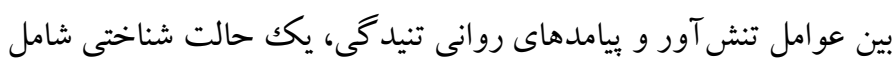

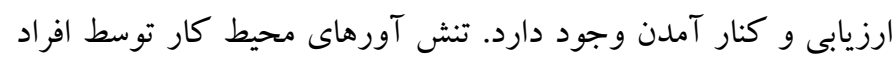

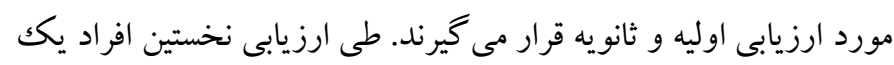

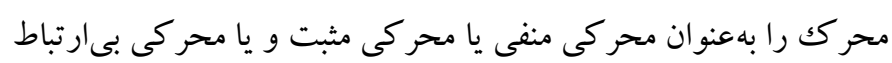

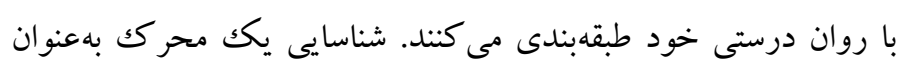

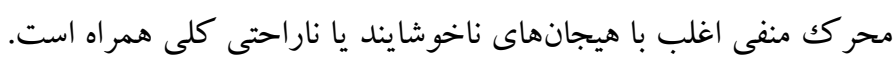

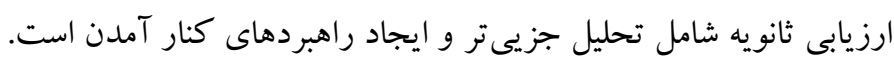

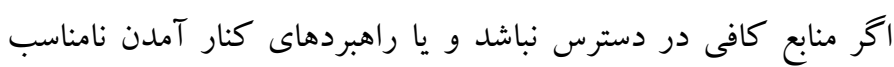

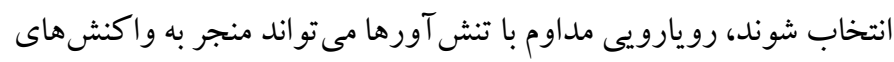

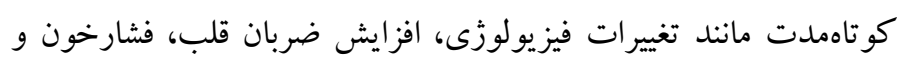

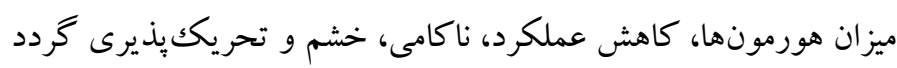

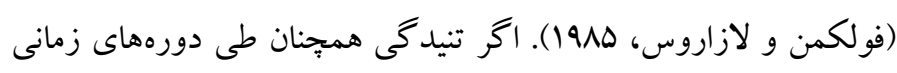

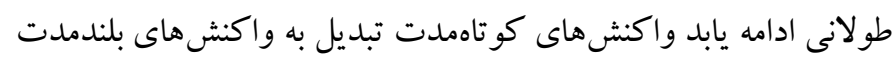

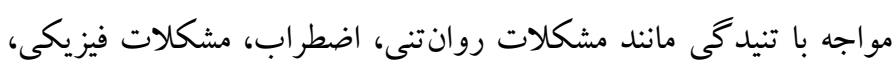

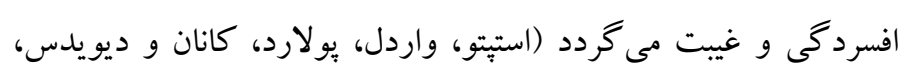

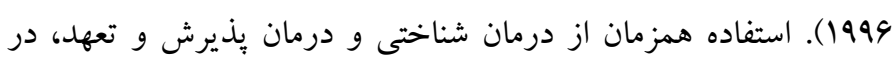

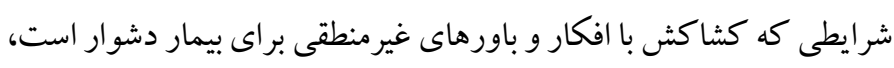

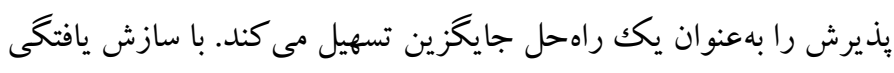

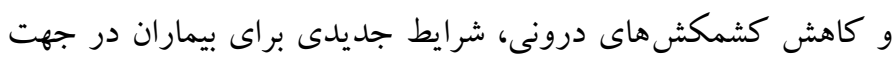

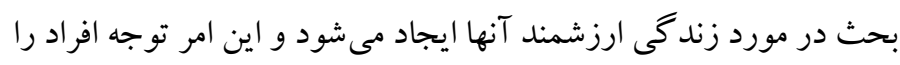

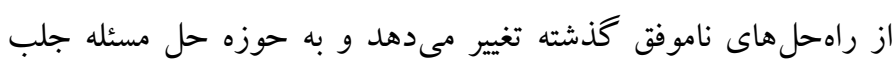

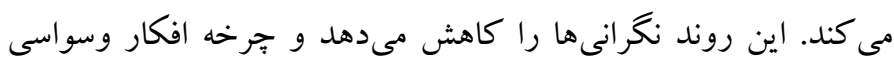
مربوط را از بين مىبرد. ازجمله محدوديت هاى اين بثروهش استفاده از ابزار

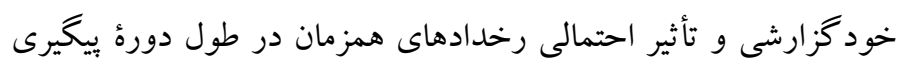

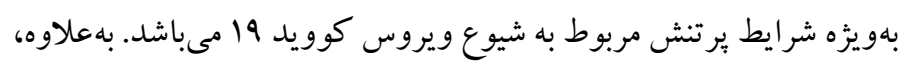

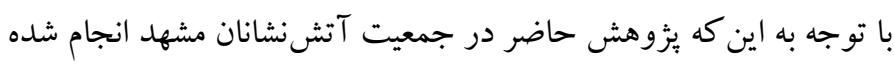

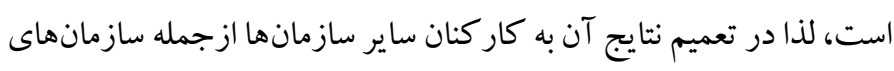

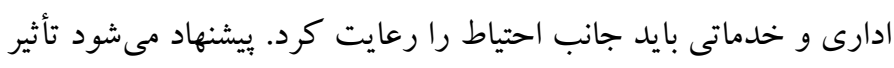

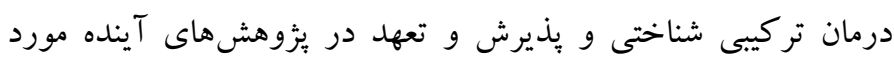

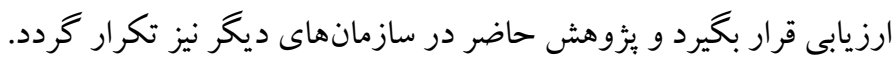


شود تا با بهبود فرد از لحاظ جسمانى و روانشناختى از تشديد علايم و يا بروز صدمات جبراننايذير جلو گيرى به عمل آيد.

ملاحضات اخلاقى

ييروى از اصول اخلاق هُوهش: اين مقاله بر گرفنه از ر ساله دكترى نويسنده اول

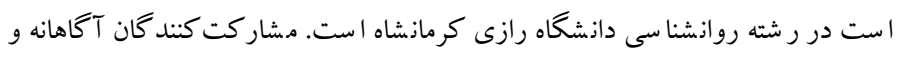

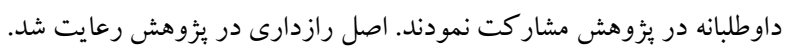
حامى مالى: اين يُزوهش در قالب رساله دكترى و بدون حمايت مالى مىباشد. نقش هر يكك از نويسند كان: نويسنده اول محقق اصلى اين يُزوهش است. نويسنده دوم استاد راهنما و نو يسند كان سوم و جهارم استادان مشاور رساله مى بـاشند. تضاد منافع: نو يسند گان هيج تضاد منافعى در رابطه با اين يزوهش اعلام نمىنمايند. ت شكر و قدردانى: بدين و سيله از ا ساتيد راهنما و مشاوران اين تحقيق و نيز كاركنان بخش منابع انسانى سازمان آتشنشانى مشهد كه در انجام اين تحقيق يارى نمودند تشكر و قدردانى مى گردد.
لحاظ روانشناختى نوعى يِش آمادگى براى بيشخيرى از تنشهاى شغلى و برخى بيامدهاى مرتبط با آن در كاركنان بهوجودآيد. بيشنهاد مىشود مسئولان شر ايطى رابراى حضور فعال روانشناسان و متخصصان روانشناسى صنعتى و سازمانى بهمنظور اشاعه جِنين آموزشهاو يا تشخيص، ارزيابى و درمان مشكلات روانشناختى كار كنان فراهم كنند. با توجه به كثرت عوامل تنش آور و شيوع تنيدكى شغلى و بيامدهايى منفى آن كه مي تواند منجر به كاهش عملكرد فردى، بهرهورى سازمانى و حتى در مواردى منجر به مشكلات جسمانى و روانشناختى مزمن براى كار كنان و هزينهاى مالى

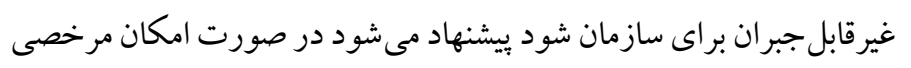
مربوط به مشكلات روانشناختى (در قالب مرخصى استعلاجى كه به تأييد متخصص روانشناسى و يا يزشك رسيده باشد) براى كار كنان در نظر كرفته 


\section{References}

AP Association (2013). Diagnostic and statistical manual of mental disorders (DSM). 5th ed. American Psychiatric Association.[Like]

A-Tjak, J. G., Davis, M. L., Morina, N., Powers, M. B., Smits, J. A., \& Emmelkamp, P. M. (2015). A metaanalysis of the efficacy of acceptance and commitment therapy for clinically relevant mental and physical health problems. Psychother Psychosom, 84, 30-36. http://dx.doi.org/10 .1159/000365764. [Link]

Babamiri, M,. Zahiri, A,. Neissi ,A,. Arshadi, N,.Shahroee, Sh.(2015). Job Stressors As Predictors Of Psychosomatic Symptoms, Journal Of Ilam University of Medical Sciences,23(1), 45-55. https://www.magiran.com/paper/1403580 [Like]

Bai, Z. Luo, S., Zhang, L., Wu, S., Chi, I., (2020). Acceptance and Commitment Therapy (ACT) to Reduce Depression: A systematic review and metaanalysis, Journal of Affective Disorders, 260, 728737.

DOI:

https://doi.org/10.1016/j.jad.2019.09.040. [Link]

Beaton, R., Murphy, S., Pike, K., \& Jarrett, M. (1995). Stress-symptom factors in firefighters and paramedics. In S. L. Sauter \& L. R. Murphy (Eds.), Organizational risk factors for job stress, 227-245. American

PsychologicalAssociation.https://doi.org/10.1037/1 0173-014. [Link]

Blackledge, J. T., Ciarrochi, J., \& Deane, F. P. (2009). Acceptance and Commitment Therapy: Contemporary theory, research and practice. Samford Valley: Australian Academic Press.[Link]

Bond, F. W., Flaxman, P. E., \& Lloyd, J. (2016). Mindfulness and meditation in the workplace: An acceptance and commitment therapy approach. The Psychology of Meditation: Research and Practice, Oxford University Press. http://research.gold.ac.uk/id/eprint/16907. [Link]

Bramwell ,K., Richardson ,T (2018). Improvements in Depression and Mental Health After Acceptance and Commitment Therapy are Related to Changes in Deffusion and Values-Based Action, $J$ Contemp Psychother, 48(1), 9-14. DOI: 10.1007/s10879017-9367-6. [Link]

Butler, A. C., Chapman, J. E., Forman, E. M., \& Beck, A. T. (2006). The empirical status of cognitivebehavioral therapy: A review of meta-analyses. Clinical Psychology Review, 26(1), 17-31. http://dx.doi.org/10.1016/j.cpr.2005.07.003. [Link]
Cayoun, B. A. (2014). Mindfulness-integrated CBT for well-being and personal growth: Four steps to enhance inner calm, self-confidence and relationships. Hoboken, New Jersey: Wiley Blackwell. [DOI:10.1002/9781118509111]. [Link]

Chung I, Lee M, Jung S, \& Nam C. (2015). Minnesota multiphasic personality inventory as related factor for posttraumatic stress disorder symptoms according to job stress level in experienced firefighters: 5-year study. Ann Occup Environ Med, 27(16), 1-8. [Link]

damiri, h. Neysi, A.k,. Arshadi, N, Na-ami, A.z. (2016). Effectiveness of Comprehensive Stress Management Training on Depression Symptoms and Psychosomatic Symptoms in Employees, Health Psychology, $\quad \uparrow \quad$ (19), 71-82. http://hpj.journals.pnu.ac.ir/article_2037.html [Like].

DeRubeis, R. J., Hollon, S. D., Amsterdam, J. D., Shelton, R. C., Young, P. R., Salomon, R. M., O'Reardon, J. P., Lovett, M. L., Gladis, M. M., Brown, L. L., \& Gallop, R. (2005). Cognitive therapy vs medications in the treatment of moderate to severe depression. Archives of General Psychiatry, 62(4), 409-416. DOI: 10.1001/archpsyc.62.4.409. [Link]

Dimidjian, S., Hollon, S. D., Dobson, K. S., Schmaling, K. B., Kohlenberg, R. J., Addis, M. E., JosephR. G., McGlinchey, B., Markley, D. K., Gollan, J. K., Atkins, D. C., Dunner, D. L., \& Jacobson, N. S. (2006). Randomized trial of behavioral activation, cognitive therapy, and antidepressant medication in the acute treatment of adults with major depression. Journal of Consulting and Clinical Psychology, 74(4), 658-670. http:// dx.doi.org/10.1037/0022006X.74.4.658. [Link]

Farmer, R. F., \& Chapman, A. L. (2008). Behavioral interventions in cognitive behavior therapy: Practical guidance for putting theory into action. American Psychological Association. http://dx.doi.org/10.1037/11664-000. [Link]

Folkman, S., Lazarus, R.S.(1985). If it changes it must be a process: study of emotion and coping during three stages of a college examination. Personality and Social psychology; 48(1),150-170. DOI: 10.1037//0022-3514.48.1.150. [Link]

Fullerton, C.S., Ursano, R.J., \& Wang, L. (2004). Acute stress disorder, posttraumatic stress disorder, and depression in disaster or rescue workers. The American journal of Psychiatry, 161 (8),1370-1376. DOI: 10.1176/appi.ajp.161.8.1370. [Link] 
Ghatreh Samani, M, najafi, M, rahimiab boogar, I.(2019). Comparing the effectiveness of acceptance and commitment therapy and physiotherapy on depression, anxiety, and stress in patients with chronic pain. Psychological science,18(74). 159169. URL : http://psychologicalscience.ir/article--) rq-fa.html [Like]

Gol parvar, M. Akbari, M (2019). The Effectiveness of Integrative Acceptance Commitment-Cognitive Behavioral Therapy (ACT-CBT) and Parent Management Training (PMT) on the Affective Capital of Adolescent Boy with Sexual Abuse, Culture of Counseling Quartely and Psychology, 10(39), 71-98. doi: 10.22054/qccpc.2019.41608.2133 [Like]

Goldberg, D. P. \& Hillier, V. F. (1979). A scaled version of the General Health Questionnaire, Psychological Medicine, $\quad 9(1)$, 139-145. https://doi.org/10.1017/S0033291700021644. [Link]

Hallis, L., Cameli, L., Bekkouche, N. S., \& Knauper, B. (2017). Combining cognitive therapy with acceptance and commitment therapy for depression: A group therapy feasibility study. Journal of Cognitive Psychotherapy, 31(3), 171190. https://doi.org/10.1891/0889-8391.31.3.171. [Link]

Hallis, L., Cameli, L., Dionne.,F., \& Knauper .,B.(2016). Combining Cognitive Therapy with Acceptance and Commitment Therapy for Depression: A Manualized Group Therapy; Journal of Psychotherapy Integration, 26(2), 186201. https://doi.org/10.1037/int0000028. [Link]

Harley, J. (2015). Bridging the gap between cognitive therapy and acceptance and commitment therapy. Procedia -Social and Behavioral Sciences, 193, 131-140. https://doi.org/10.1016/j.sbspro.2015.03.252. [Link]

Harvey, S.B., Milligan-Saville, J.S., Paterson, H.M., Harkness, E.L., Marsh, A.M., Dobson, M., Kemp, R., \& Bryant, R.A. (2016). The mental health of fire-fighters: An examination of the impact of repeated trauma exposure. Aust $N Z J$ Psychiatry. 50(7),649-658. DOI: 10.1177/0004867415615217. [Link]

Haslam, C, \& Mallon K. (2003).A preliminary investigation of post-traumatic stress symptoms among firefighters. Work and Stress, 17(3), 277285. DOI: 10.1080/02678370310001625649. [Link]
Hatami, M., Hasani, J., Ghasemi. M. (2014). The effectiveness of cognitive behavior therapy on mindfulness, resiliency and quality of life in patients with chronic pain. Journal of Psychological Science, 13(51). 364-375. URL: http://psychologicalscience.ir/article-r $\wedge_{-}$-) -fa.html [Like].

Hayes, S. C. (2019). Acceptance and commitment therapy: towards a unified model of behavior change. World Psychiatry,18(2), 226- 227. DOI: 10.1002/wps.20626. [Link]

Herbert, J. D., \& Forman, E. M. (2013). Caution: The differences between CT and ACT may be larger (and smaller) than they appear. Behavior Therapy, 44, 218-223. http://dx.doi.org/10.1016/j.beth 2009.09.005. [Link]

Hoke, C. (2003). The effectiveness of an electronic-mail campaign to modify stress levels, mood states, and coping techniques among employed adults. dissertation, University of North Texas Libraries, UNT

Digital

Library, https://digital.library.unt.edu;[Like]

Jackson, C., (2007). The general health questionnaire. Occupational Medicine; 57(1):79. https://doi.org/10.1093/occmed/kql169. [Link]

Joyce, S., Modini, M., Christensen, H., Mykletun, A., Bryant, R., Mitchell, P., \& Harvey, S. (2016). Workplace interventions for common mental disorders: a systematic meta-review. Psycho Med. ; 46(4),683-697.

DOI: 10.1017/S0033291715002408.

[CrossRef] [Google Scholar]. [Link]

Khesmakhi, S. S., Afshar Zanjani, H., Goli,F., Omidi, A., Scheidt, C. E., \& Givehki, R., (2019). Effectiveness of Acceptance and Commitment Therapy on Psychosomatic Symptoms and Mindfulness in Patients with Psychosomatic Disorder. Journal of Practice in Clinical Psychology, 7(2), 79-86. http://dx.doi.org/10.32598/jpcp.7.2..79. [Link]

Kiani, S, Sabahi, P, Makvandhosaini, Sh, Rafieinia, P, Alebouyeh, M (2020). Comparison of the effectiveness of acceptance and commitment-based therapy and positive cognitive-behavioral therapy on the pain self-efficacy of patients with chronic pain, Journal of psychological science. 19(89), 567578.

https://www.sid.ir/fa/journal/ViewPaper.aspx?id=d .9 . 99 [Like]

Lau, R, W. M. ;Mak W. H., (2017) Effectiveness of Workplace Interventions for Depression in Asia: A 
Meta-Analysis, Sage journals, 7 (2).1-17. https://doi.org/10.1177/2158244017710293. [Link]

Leahy, R., Tirch, D., \& Napolitano, L. (2011). Emotional regulation in psychotherapy.A Practitioners Guide. New York, NY: Guilford Press. ;[Like]

lerner, D., Adler, D.A., Chang, H., Lapitsky,L., Hood,M.Y.,Perissinotto,C.,Reed,J.,McLaughlin,T,J .,Berndt,E,R \& Rogers,W,H. (2004). Unemployment, job retention, and productivity loss among employees with depression". Psychiatric Services, 55(12), 1371-1378. DOI: 10.1176/appi.ps.55.12.1371. [Link]

Lima, E.D., Assuncao, A., Barreto, S.M., (2015). Prevalence of depression among firefighters. Nacional de Saude Publica, 31 (4), 733743.[PubMed]. [Link]

Lunde, L. H., \& Nordhus, I. H. (2009). Combining acceptance and commitment therapy and cognitive behavioral therapy for the treatment of chronic pain in older adults. Clinical Case Studies, 8(4), 296308. http://dx.doi.org/10.1177/1534650109337527. [Link]

Matsuoka, H., Chiba, I., Sakano, Y., Toyofuku, A., \& Abiko, Y. (2017). Cognitive behavioral therapy for psychosomatic problems in dental settings. BioPsychoSocial Medicine, 11(18),. [DOI: 10.1186/s13030-017-0102-z] [PMID] [PMCID]. [Link]

McCracken, L. M., \& Vowles, K. E. (2014). Acceptance and Commitment Therapy and mindfulness for chronic pain: Model, process, and progress. The American Psychologist, 69(2), 178-187. [DOI: 10.1037/a0035623] [PMID]. [Link]

Mein, G., Martikainen, P., Stansfeld, S. A., Brunner, E. J., Fuhrer, R., \& Marmot, M. (2000). Predictors of early retirement in British civil servants. Age Ageing; 29(6), 529-5 36. DOI: 10.1093/ageing/29.6.529. [Link]

Menin, D.S., Ellard, K.K. Fresco, D.M. \& Gross, J.J. (2013). United we stand: Emphasizing commonalities across cognitive-behavior therapies. Behavior Therapy, 44(2), 234-248. DOI: 10.1016/j.beth.2013.02.004. [Link]

Mohr, G. B, (2000). The changing significance of different stressors after the announcement of bankruptcy a longitudinal investigation with special emphasis on job insecurity. Journal of Organizational Behavior https://www.jstor.org/stable/3100337. [Link] 21(3),337-359.

Nelson, K.V., \& Smith, A.P., (2016). Occupational stress, coping and mental health in Jamaican police officers. Occupy Med. 66 (6), 488-491. DOI: $10.1093 /$ occmed/kqw055. [Link]

Orsillo, S. M., Roemer, L., \& Barlow, D. H. (2003). Integrating acceptance and mindfulness into existing cognitive-behavioral treatment for GAD: A case study. Cognitive and Behavioral Practice, 10(3), 222-230. http://dx.doi.org/10.1016/S10777229 (03)80034-2. [Link]

Rashidi, M. A., Pournajaf, A., Kazemy M, Kaikhavani, S.(2018). Evaluating General Health Status using Goldberg's General Health Questionnaire among the Staff of Ilam University of Medical Sciences, Journal Of Ilam University Of Medical Sciences ,23 (3) :16-26.URL :http://sjimu.medilam.ac.ir/article1-3714-fa.html [Like]

Rocque, C.L., Harkness, K.L., \& Bagby, R.M., (2014). The differential relation of childhood maltreatment to stress sensitization in adolescent and young adult depression. Journal of Adolescence. 37 (6), 871882. DOI: 10.1016/j.adolescence.2014.05.012. [Link]

Sakuma, A., Takahashi, Y., Ueda, I., Sato, H., Katsura, M., Abe, M., Nagao, A., Suzuki, Y., Kakizaki, M., Tsuji, I., Matsuoka, H., \& Matsumoto, K. (2015). Post-traumatic stress disorder and depression prevalence and associated risk factors among local disaster relief and reconstruction workers fourteen months after the Great East Japan Earthquake: a cross-sectional study. BMC Psychiatry, 15(58),1-13. DOI: 10.1186/s12888-015-0440-y. [Link]

Sanchez,B, S., Gil Roales-Nieto, J,G., Ferreira, N. B., Gil Luciano, B., \& Domingo, J.J. S., (2017). New psychological therapies for irritable bowel syndrome: Mindfulness and Acceptance and Commitment Therapy (ACT). Revista Española de Enfermedades Digestivas, 109(9), 648-657. [DOI: 10.17235/ reed.2017.4660/2016] [PMID]. [Link]

Schepis, T. S., Rao, U., Yadav, H., \& Adinoff, B. (2011). The limbic-hypothalamic-pituitary adrenal axis and the development of alcohol use disorders in youth. Alcohol. Clin. Exp. Res, 35(4), 595-605. DOI: 10.1111/j.1530-0277.2010.01380.x. [Link]

Smith, T.D., DeJoy, D., M., Dyal, M-A., \& Huang, G. (2019). Impact of Work Pressure, Work Stress and Work-Family Conflict on Firefighter Burnout, Archives of Environmental \& Occupational Health,74(4),215-222. DOI: 10.1080/19338244.2017.1395789. [Link]

Tan, L., Wang, M. J., Modini, M., Joyce, S., Mykletun, A., Christensen, H., \& Harvey, S. B. (2014). Preventing the development of depression at work: 
a systematic review and meta-analysis of universal interventions in the workplace, BMC Medicine, 12(74),1-11. DOI: 10.1186/1741-7015-12-74. [Link]

Wong, J. Y., Lin, J. H ., Liu S. H., Wan, T. H. (2014). Fireman's job stress: Integrating work/non-work conflict with job Demand-Control-Support model. European Review of Applied Psychology, 64(2), 8391. [Like]

World Health Organization (2017). Depression: "Let's talk" says WHO, as depression tops list of causes of ill health. Geneva: World Health Organization Link: https://bit.ly/2rsqQoP. [Link]

World Health Organization. (2019). Mental health in the workplace

https://www.who.int/mental_health/in_the_workpl ace/en/. [Link]

Yunus, W.M.A.W., .M., Musiat. P., \& Brown, J.S.L. (2018). Systematic review of universal and targeted workplace interventions for depression. Occup Environ Med. 75(1),66-75. DOI: 10.1136/oemed2017-104532. 